\title{
THE EFFECTS OF ANTI-PRICE GOUGING LEGISLATION ON SUPPLY CHAIN DYNAMICS
}

\author{
A Thesis \\ presented to \\ the Faculty of California Polytechnic State University, \\ San Luis Obispo
}

\author{
In Partial Fulfillment \\ of the Requirements for the Degree \\ Master of Science in Industrial Engineering
}

by

Jason E. Maynard

December 2010 
(C)2011

Jason E. Maynard

\section{ALL RIGHTS RESERVED}




\section{COMMITTEE MEMBERSHIP}

TITLE:

AUTHOR:

DATE SUBMITTED: January, 2011

COMMITTEE CHAIR: Dr. Reza Pouraghabagher

COMMITTEE MEMBER: Dr. Roya Javadpour

COMMITTEE MEMBER: Dr. Unny Menon Supply Chain Dynamics

Jason E. Maynard

The Effects of Anti-Price Gouging Legislation on 


\section{ABSTRACT \\ The Effects of Anti-Price Gouging Legislation on Supply Chain Dynamics}

Jason E. Maynard

The purpose of this thesis is to model the effects of anti-price gouging (APG) legislation on the costs to businesses during the recovery period of a disaster. A system dynamics model of a business's replenishment procedures is used to simulate the effects of APG legislation on business performance. Economists have published expansive research on the effects of price ceilings on supply and demand, but there is little research evidence on the operational consequences of price ceiling legislation on business costs. APG legislation increases consumer's forward buying and shortage gaming after a disaster by removing price incentives to be frugal. Forward buying and shortage gaming are two key drivers of the demand variation and the bullwhip effect, which leads to increased inventory costs, misguided capacity expansion and reduced service levels. These costs have a negative impact on local businesses that are critical to a community's economic health and recovery from a disaster. The simulation results from this thesis show that APG legislation is not an effective regulatory response to decrease the impact of disasters on affected communities.

Keywords: Anti-price gouging legislation, supply chain dynamics, disaster recovery planning, beer game 


\section{ACKNOWLEDGEMENTS}

I would to thank my advisor, Dr. Reza Pouraghabagher, for encouraging me to focus on an area with a positive impact on the humanitarian research. I would also like to thank Dr. Unny Menon and Dr. Roya Javadpour for their contributions and feedback as my thesis committee members. Lastly, I want to thank my family for their love and support through my time at Cal Poly. 


\section{TABLE OF CONTENTS}

List of Tables .............................................................................................. vii

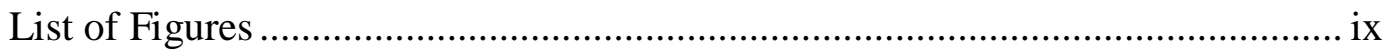

Chapter 1: Introduction ............................................................................. 1

Chapter 2: Literature Review........................................................................ 4

2.1 Disaster Management Research ................................................................. 4

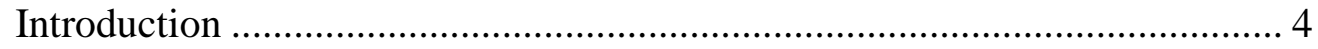

What is Disaster Management Research? ................................................... 5

Current State of Disaster Management Research ........................................... 6

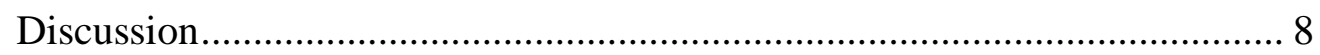

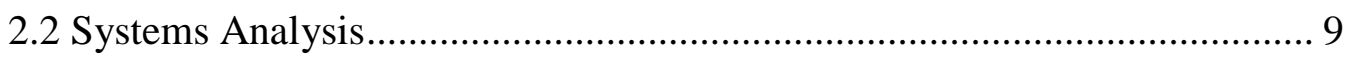

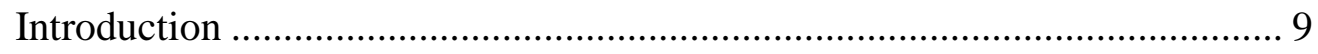

System Thinking and Soft Operations Research ........................................... 10

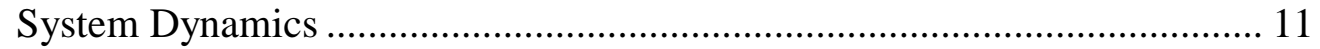

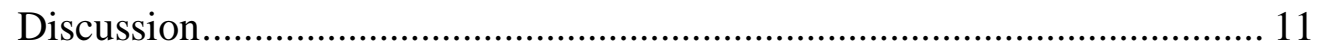

2.3 Anti-Price Gouging Legislation ............................................................. 12

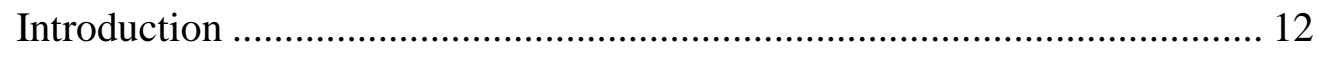

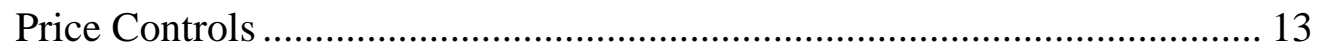

Anti-Price Gouging Legislation............................................................... 13

Current Anti-Price Gouging Legislation in the United States....................... 14

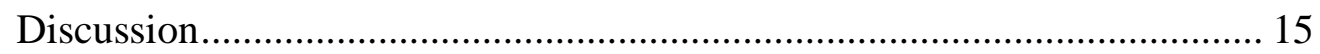

2.4 Supply Chain Management and The Beer Game ......................................... 16

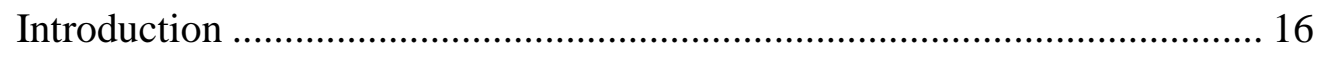

The Bullwhip Effect in the Real World..................................................... 17

History of the Beer Game ........................................................................ 18

Description The Beer Game …………................................................ 18

Patterns of Behavior in the Beer Game ..................................................... 21

Causes of the Bullwhip Effect.................................................................. 22

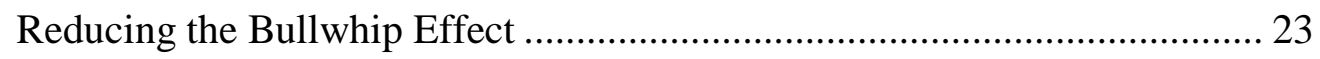

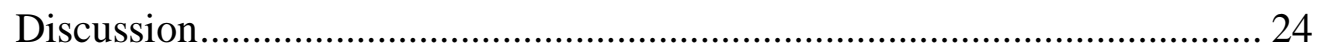

2.5 Simulating the Beer Game with System Dynamics ………......................... 25

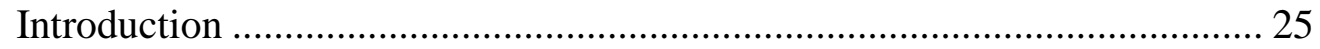


The Beer Game System Dynamics Model .............................................. 26

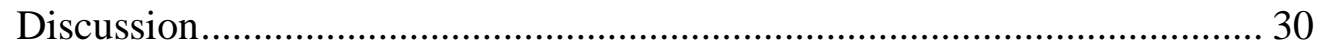

2.6 Economic Analysis of Anti-Price Gouging Legislation........................... 31

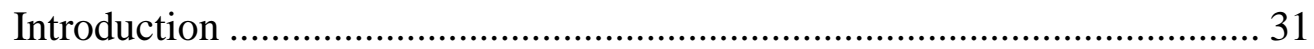

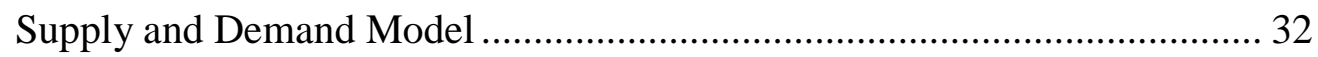

Macroeconomic Analysis of Price Ceilings ............................................ 32

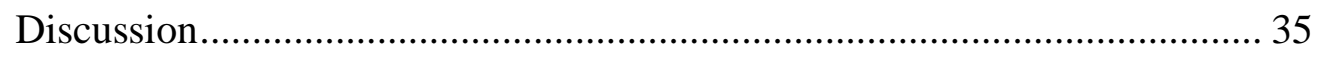

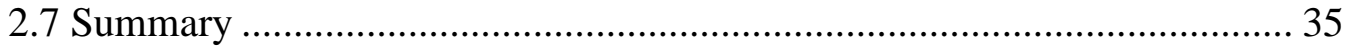

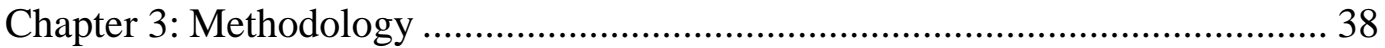

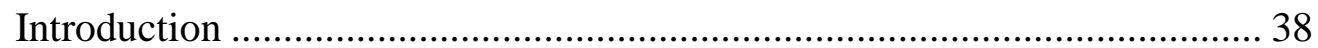

System Dynamics Simulation Model ..................................................... 38

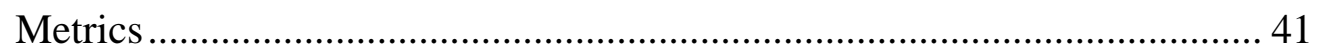

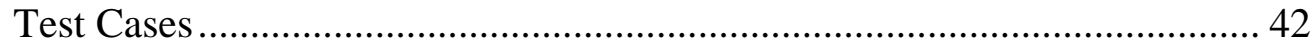

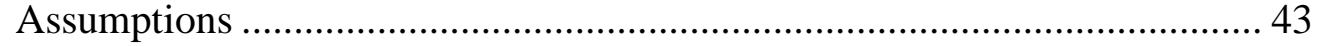

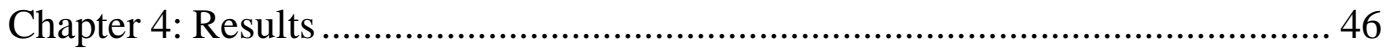

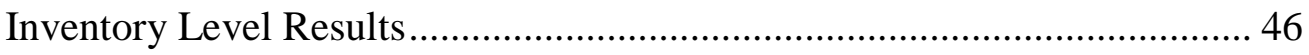

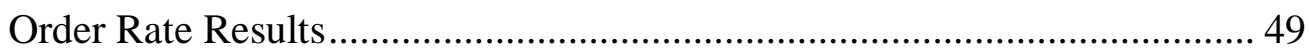

Units Sold, Price and Demand Results ................................................... 52

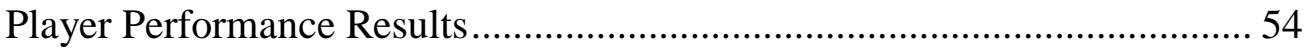

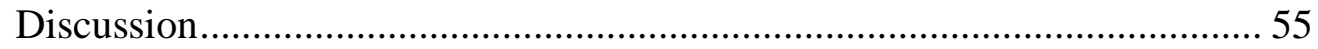

Chapter 5: Conclusion and Future Work ........................................................ 58

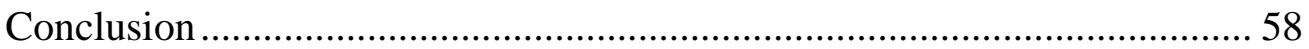

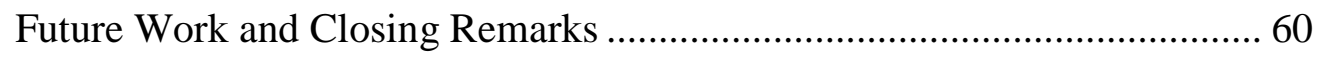

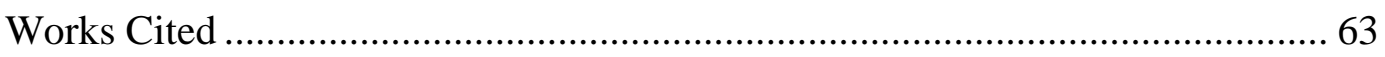

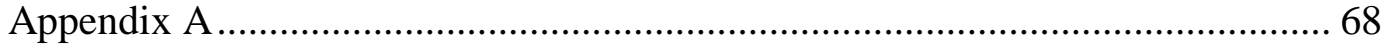

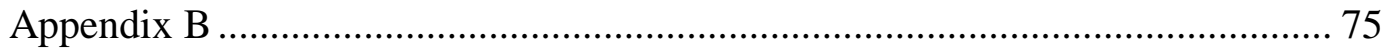

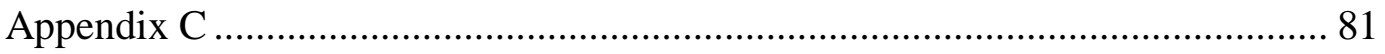

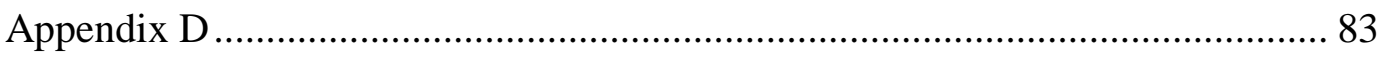




\section{LIST OF TABLES}

Table 1 Effective inventory statistics summary ............................................... 48

Table 2 Vensim equations for beer game model (Kirkwood, 2010).................... 68

Table 3 Vensim equations for the integrated supply chain model ...................... 70

Table 4 Effective inventory for Case I (No legislation) ................................... 75

Table 5 Effective inventory for Case II (Price rigidity)..................................... 76

Table 6 Effective inventory for Case III (APG legislation) ............................... 77

Table 7 Orders placed for Case I (No legislation) …........................................ 78

Table 8 Orders placed for Case II (Price rigidity) ............................................. 79

Table 9 Orders placed for Case III (APG legislation) ...................................... 80

Table 10 Anti-price gouging legislation by state (Davis, 2008) ........................ 83 


\section{LIST OF FIGURES}

Figure 1 Percentage of DMR by methodology (Altay \& Green III, 2006)............ 7

Figure 2 Percentage of DMR by research type (Altay \& Green III, 2006) ............ 7

Figure 3 Percentage of DMR by disaster stage (Altay \& Green III, 2006) ............ 8

Figure 4 Beer game flow chart.................................................................... 19

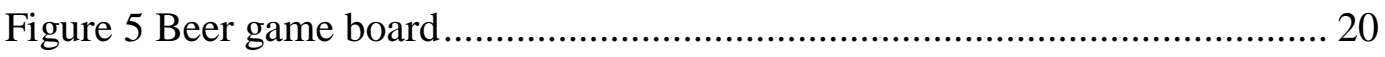

Figure 6 Beer game stock and flow diagram (Kirkwood, 2010) ........................ 29

Figure 7 Beer game stock and flow diagram Pg.2 (Kirkwood, 2010) .................. 30

Figure 8 Traditional supply and demand model of price ceilings ...................... 34

Figure 9 Causal diagram of dynamic supply and demand model....................... 40

Figure 10 Stock and flow diagram for market integrated supply chain model..... 41

Figure 11 Effective inventory levels for Case I, II and III................................ 46

Figure 12 Orders placed at each supply chain location ..................................... 49

Figure 13 Order deviation from actual demand for Case I and Case III.............. 50

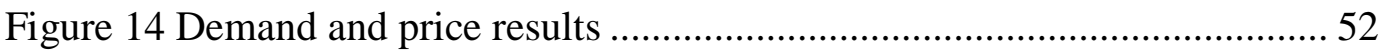

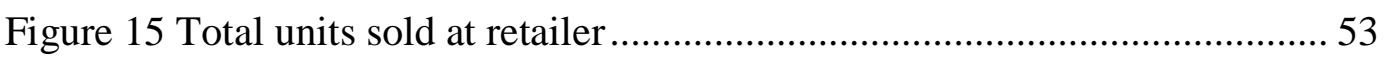

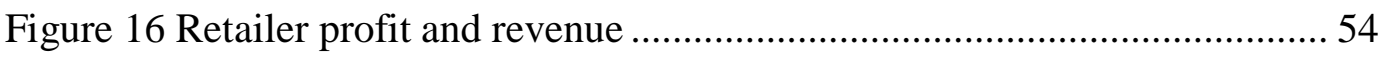

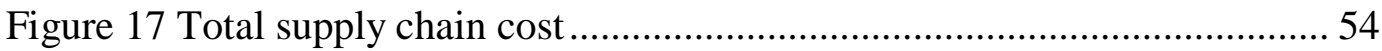




\section{CHAPTER 1: INTRODUCTION}

Regions that have been affected by disasters are characterized by

turbulence, uncertainty and compassion for those who have been affected. Local businesses are faced with the daunting task and added responsibility of providing goods that are critical to the wellbeing of their communities, while simultaneously adapting to new challenges and costs that threaten their existence. Disasters are low probability, but high impact events that have huge ramifications on business performance, but are often underprepared for because of their infrequent and random nature.

Anti-price gouging (APG) legislation is a type of state enforced price ceiling implemented during a government declared state of emergency. APG legislation prevents local businesses from raising prices on energy and general goods above pre-emergency prices. Thirty-one US states have enacted APG legislation in the last thirty years in order to protect those affected by disasters. APG legislation is implemented with the intention of reducing two potential consequences of a shortage created by a disaster. (1) To protect those who are in poverty from price increases that could prevent them from securing essential goods or services and (2) prevent businesses from unfairly profiting from those who are subjected to shortages in supply after a disaster.

Traditional macroeconomic analysis of price ceilings has been used to show the negative effects of price controls on incentives for businesses to acquire additional supply lines and removal of value-based market allocation mechanisms. Savings through price ceilings are dispersed through additional 
allocation costs, such as the cost of waiting in lines. Additionally, macroeconomic analysis shows that price ceilings actually exacerbate shortages because of diminished or eliminated incentives for suppliers to secure new capacity and removal of incentives for consumers to ration the remaining supplies. Although there has been ample research into macroeconomic affects of price controls, there is a significant lack of research on the operational effects on business processes. In an investigation of price gouging done by the Federal Trade Commission (FTC) after Hurricane Katrina there was no analysis of the additional operational costs to businesses caused by volatile demand conditions (Federal Trade Commission, 2006). This research addresses the operational consequences of APG legislation on businesses in areas affected by a disaster.

APG legislation increases costs in a supply chain by removing the mechanism of price fluctuation to dampen demand volatility after a disaster. Fears of supply shortages after a disaster propagate severe demand variations, leading to large variations in ordering patterns for retailers in the affected area. Demand spikes are amplified in upstream suppliers in a phenomenon known as the bullwhip effect. The bullwhip effect causes demand shifts to be amplified through a supply chain, creating deviations between actual and perceived demand that increase inventory and capacity investment costs, while simultaneously reducing service levels.

By hampering local business profitability, APG legislation reduces the ability of a region's economy to recover from a disaster and may prolong the suffering of those affected. In order to model the effects of APG legislation, two 
methodologies are utilized. A traditional economic supply and demand model is used to show the macroeconomic effects of APG legislation. Next, a system dynamics model of the beer game integrated with a dynamic pricing model is used to analyze the effects of demand spikes on inventory levels and costs with and without APG legislation. This thesis supplements disaster recovery research and economic analysis of price controls to give legislators a more complete view of the causes of poor economic performance and business failure stemming from conditions of high demand volatility after a disaster. 


\section{CHAPTER 2: Literature REVIEW}

Thoughtful leaders increasingly recognize that we are not only failing to solve the persistent problems we face, but are in fact causing them. System dynamics is designed to help avoid such policy resistance and identify high-leverage policies for sustained improvement.

(Sterman, 2002)

\subsection{DiSASTER MANAGEMENT RESEARCH}

\section{INTRODUCTION}

In the past five years, major natural disasters such as the Indian Ocean Tsunami in 2004, Hurricanes Katrina and Rita in 2005 and the earthquakes in Qinghai, China and Port-au-Prince, Haiti in 2010 and many other smaller scale disasters have led to an increasing evaluation of disaster management research. Disasters pose major threats to human life, personal property, infrastructure and regional economic performance. Often, the people who are affected the most by disasters are the poor and disenfranchised, who lack the means necessary to improve their situations. To date there has been little research of disaster recovery issues in management science or operations research literature.

This section explores the current state of research into disaster management. Disaster management research is focused on improving communities that have been marginalized by disasters or emergencies through strategies that address mitigation, preparation, response and recovery. Disaster management research aids in managing and allocating resources and information to aid people and businesses that are affected in the wake of a disaster. The 
research in this area is targeted at those who have management authority over response efforts, such as governments, aid agencies and businesses.

\section{WHAT IS DISASTER MANAGEMENT RESEARCH?}

Disaster management research (DMR) activities fall into four sets that are performed before, in prediction of, during, and after a disaster or mitigation, preparedness, response and recovery, respectively (Altay \& Green III, 2006).

DMR is concerned with issues that go beyond routine response to emergencies of paramedics, police and fire departments. DMR is aimed at discovering improvements to the architecture, processes, policies and tools that are used in the mitigation, preparedness, response and recovery to emergencies (Quarantelli, 1988). The application of quantitative decision modeling techniques, such as operations research (OR) and management science (MS), can be applied effectively to disaster management research to improve the disaster outcomes (Bryson, Millar, Joseph, \& Mobolurin, 2002).

Winston defines management science and operations research as a scientific approach to decision making which seeks to determine how best to design and operate a system, usually under conditions requiring the allocation of scarce resources (Winston, 1997). In the case of disaster management, the goal is preventing loss of human life, reducing its impact on the economy, and returning to a state of normalcy. Response to earthquakes, hurricanes, cyclones, typhoons, tsunamis, floods, droughts, volcanic eruptions, epidemics, famines, man-made disasters and biological and technological disasters are all covered under the domain of disaster management research (Quarantelli, 1998). 


\section{CURRENT StATE OF DisASTER MANAGEMENT RESEARCH}

A survey done on the current state of academic research done on disaster management research shows that it covers a range of methodologies including (Altay \& Green III, 2006):

- Mathematical, Constraint \& Stochastic Programming

- Probability and Statistics

- Multi Attribute Utility Theory (MAUT)

- Simulation

- Decision \& Queuing Theory

- Fuzzy Sets

- Expert Systems

- Artificial Intelligence (AI)

- Systems Dynamics

Figure 1 below shows a breakdown of the areas of study for DMR.

Mathematical programming and heuristic approaches to solutions are the most heavily researched, followed closely by statistics and probability research. The most under-researched areas are system dynamics, constraint programming and soft operations research. Soft operations research is the study of methods for strategic planning, decision support systems and problem structuring methods (PSM), where mathematical modeling and simulation are not appropriate or will not suffice (Lancaster University - Management School, 2010). 


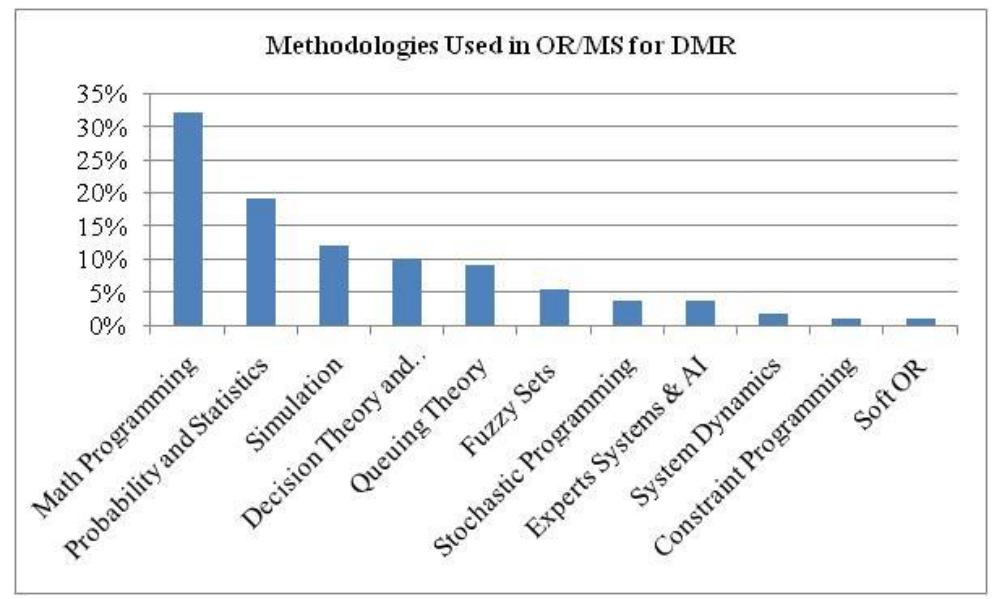

Figure 1 Percentage of DMR by methodology (Altay \& Green III, 2006)

Figure 2 and Figure 3 below are a breakdown of the applications and disaster stages covered in the academic literature for operations research (OR) and management science (MS). Modeling is the most studied and application is the least studied area of OR/MS, at $58 \%$ and $13 \%$ of peer reviewed journal papers, respectively. The most heavily OR/MS researched disaster stage is the mitigation stage and the least studied area is the recovery stage at $44 \%$ and $11 \%$ of peer reviewed journal papers, respectively.

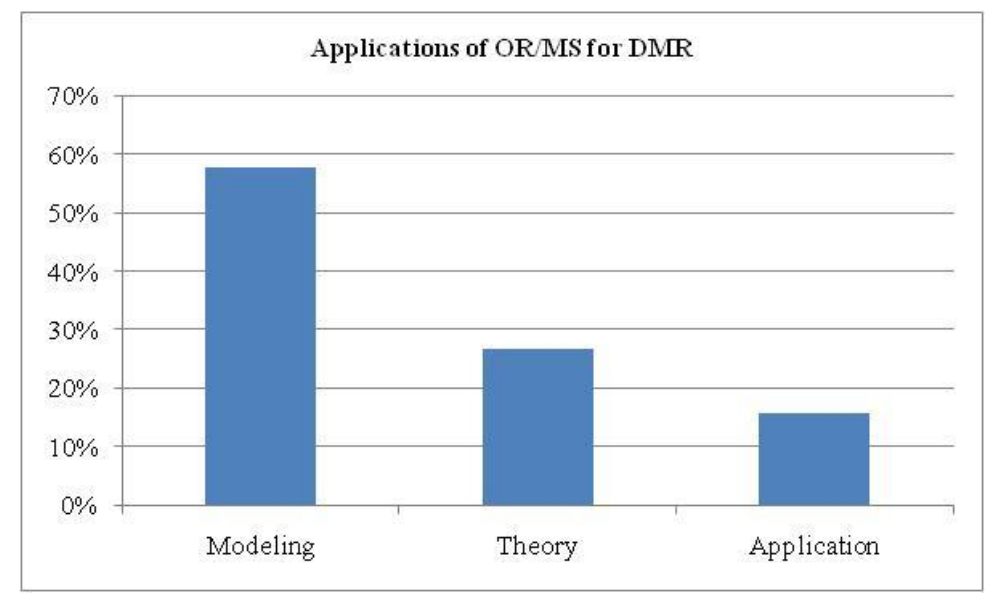

Figure 2 Percentage of DMR by research type (Altay \& Green III, 2006) 


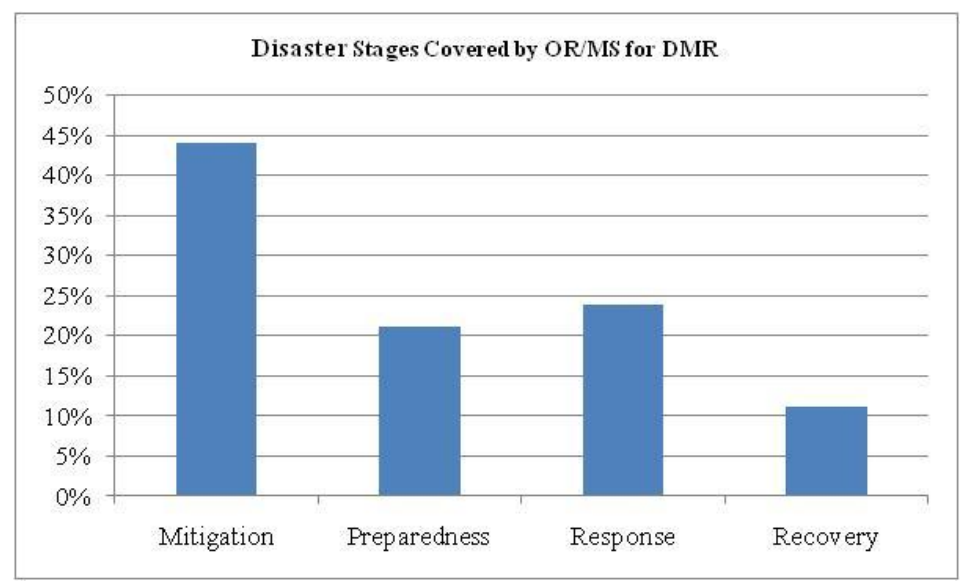

Figure 3 Percentage of DMR by disaster stage (Altay \& Green III, 2006)

There is a need to address problems with respect to the development of coordination between business and government in areas affected by disasters (Quarantelli, 1986). The area in dire need for more research is the disaster recovery stage (Altay \& Green III, 2006). Only one article on recovery planning was published in main stream operations research and management science journals (Bryson, Millar, Joseph, \& Mobolurin, 2002). The definition of recovery planning is "any activity that involves the actions taken in the long term after the immediate impact of the disaster has passed to stabilize the community and to restore some semblance of normalcy" (Altay \& Green III, 2006). Not surprisingly, this area of research is also the most appropriate for applications of fuzzy systems, system dynamics and soft operations research, which are the most underutilized methodologies in the current academic research in this field.

\section{DISCUSSION}

Based on the state of the current research, there is a need to further modeling of government policy effects on disaster recovery. The recovery stage of DMR includes the policies, procedures and regulations that are used after a 
disaster to restore a community to a state of normalcy. This area of research is critical to ensuring organizations operate effectively during the aftermath of a disaster (Bryson, Millar, Joseph, \& Mobolurin, 2002). There is a need for research into coordination between government and private sector in addressing disaster issues. One such interoperating policy is anti-price gouging (APG) legislation. APG legislation is an area where state government regulation affects private sector decision making during the recovery stage of a disaster.

APG legislation is enacted after a disaster in a state of emergency (SOE) and mandates constraints on prices that retailers can charge for goods and services after a disaster. This directly affects decision making of consumers and businesses during an economic recovery from a disaster. Research into APG legislation involves modeling of policy effects, which is often difficult to accomplish because of their inherent complex nature, nonlinearities and numerous intangibles (Mingers \& Resenhead, 2004). In order to create a framework to evaluate the effects of APG legislation on business costs, a soft operations research and system dynamics methodology is utilized, which is discussed in the next section.

\subsection{SYSTEMS ANALYSIS}

\section{INTRODUCTION}

In our complex world, the ability to evaluate problems holistically is becoming increasingly critical. Psychological studies have identified numerous cognitive, temporal and other limitations, which inhibit human's ability to make rational choices in complex environments causing errors and biases in judgment 
and choice (Sterman, 1989). System dynamics and soft operations research are designed to help decision makers test their assumptions about outcomes in complex systems. Soft OR techniques are aptly suited to the modeling of complex environments allowing for more influential and cohesive mental models that lead to more thorough analysis.

A system is defined as an integrated series of parts or processes with a defined goal (Scholtes, 1998). In order to evaluate the effects of APG legislation on supply chain costs, the system is studied is the replenishment decision making process of a business. Supply chain is an umbrella term used for the activities a business undertakes in order to link their supply of goods with customer demand. Complex organizational systems, such as supply chains, can often produce behavior and results that are not intuitive by nature and can benefit from system analysis techniques.

\section{SySTEM THINKING AND SOFT OPERATIONS RESEARCH}

Soft operations research has evolved during the last decade in a reaction to the inability of hard operations research to address issues of increased complexity that cannot be modeled with traditional operations research (OR) techniques (Forrester, 1994). In many of these more complex realms the application of linear programming, queuing theory, regression analysis, scheduling algorithms and Monte Carlo simulation cannot capture the dynamic nature of processes in the real world (Forrester, 1994).

Traditional scientific approaches to problem solving emphasize looking for causal chains rather than loops. This creates a process that continually looks 
for the cause of an event, but inevitably there is another event that caused a previous event (Senge, 1990). System thinking and soft OR emphasizes identifying patterns of behavior and then determining the structures that propagate those patterns, which allows for sustaining changes in patterns of behavior. There is a symbiotic relationship between a soft $\mathrm{OR}$ and system thinking approaches to problem solving and the system dynamics modeling framework. The combination of techniques allows for common mental models of a system to be created and tested (Forrester, 1994).

\section{SYSTEM DYNAMICS}

System dynamics is a methodology and computer simulation technique for framing, understanding, and discussing complex issues and problems. The benefits of the system dynamics simulation framework is that it can accept complexity, non linearity and feedback loop structures that are inherent in social, political and physical systems. By creating a common quantitative mental model, a team of analysts can test the assumptions and evaluate the effects of changes in variables, structures and policies. The fields of economics, social science, IT, management and engineering all contribute to the bodies of knowledge that contribute to the behavior of social, economic and business systems (Forrester, 1961). System dynamics helps bridge the gap between disciplines, allowing for collaboration and simulation of test scenarios within these environments.

\section{DISCUSSION}

System thinking and soft OR involves gaining a deep understanding of how systems function. Although this is a critical first step, this process lacks a 
quantitative base and instead relies solely on intuition and discussion. System dynamics creates a flexible quantitative framework that allows for rigorous testing of mental models. For this reason, system dynamics is an apt methodology to simulate the effects of APG legislation on disaster recovery. Business failure and its subsequent consequences can rarely be linked to a single cause, but in difficult financial times created by a disaster, understanding the operational effects of legislation will aid economists and policy makers in understanding the macro effects of their decisions. System dynamics has a flexible simulation framework that can accept the relationships necessary to model in complex legislative and social environments.

A system dynamics simulation will be used to create a testable mental model for the effects of APG legislation on supply chain dynamics. This will allow legislators to evaluate the long term effects of their decisions on business costs and to better understand the affects of policies on everyday business functions. In order to accurately model the effects of APG legislation, the details of the legislation are summarized in the next section.

\subsection{ANTI-PRICE GOUGING LEGISLATION}

\section{INTRODUCTION}

This section provides details on price control and anti-price gouging (APG) legislation in the United States. APG legislation is a type of state enforced price ceiling that is enacted when a state of emergency (SOE) is declared. The legislation is intended to prevent businesses from raising prices for critical goods and energy supplies during shortages created by a disaster. The history of price 
controls and its relevance to modern day APG legislation is covered. The details of APG legislation and their extent in the United States are then summarized.

\section{PRICE CONTROLS}

Government enforced price controls have had a long history, dating back to medieval monarchies fixing the maximum price of bread, to recent years where the United States have fixed the price of gasoline, the rent on apartments in New York City, and the wages of unskilled labor (Rockoff, 1984). Price controls, particularly price ceilings are implemented out of concern for groups who may have difficulty securing resources necessary to obtain critical goods and services (Rockoff, 2008).

\section{ANTI-PRICE GOUGING LEGISLATION}

The price controls that are focused on in this thesis are a type of price ceiling legislation called anti-price gouging (APG) legislation. APG legislation is state level legislation that is enacted in a state of emergency (SOE) or during abnormal market conditions. APG legislation prevents businesses from increasing prices above either pre-emergency prices or a percentage increase of the initial price before the disaster. The legislation is only effective when there are pressures for prices to increase in the time of a shortage and do not prevent prices from decreasing below the pre-disaster levels.

Politicians are often under pressure to enact APG legislation to show compassion for those affected (Davis, 2008). Although economists generally disagree with price ceilings because they tend to aid some consumers and hurt 
others, price controls hold the promise of protecting groups that are particularly hard-pressed to meet price increases (Rockoff, 2008).

\section{CuRRent Anti-Price Gouging LEGISLATion in the United States}

In 2008, thirty-one states had active APG legislation with varying regulation on prices and goods covered by the regulation (Davis, 2008). 16 of the 31 state's APG legislation have been enacted in the last 10 years, many coming in response to Hurricanes Rita and Katrina. The fines for price gouging range from $\$ 1,000$ to $\$ 10,000$ per infraction and up to a year in prison for those found guilty.

APG legislation is not always in effect. Fifteen out of the thirty-one states activate the legislation when a state of emergency (SOE) is declared. The remaining states define the active legislation time more ambiguously, with triggering events such as "abnormal economic conditions", "market disruption" or "in the event of a disaster." The goods covered under APG legislation are generally similar. Twenty-four out of the thirty-one states laws apply to general goods and energy resources. Indiana, Massachusetts and Vermont legislation only covers petroleum and energy products.

A survey of the legislation shows that there is some variation in the way that states define price gouging. Eighteen out of the thirty-one states define gouging as any level that is above pre-emergency prices and 8 out of the 31 define gouging as any prices that is more than $10-25 \%$ higher than pre-emergency prices. The remaining states define gouging in a much more ambiguous way. These states describe price gouging as price that is "unconscionably" or "exorbitantly" 
excessive. A full summary of APG legislation by state can be found in Appendix

D.

\section{DISCUSSION}

There is APG legislation in the majority of US states. The goal of APG legislation is to prevent anti-competitive behavior and protect consumers after a disaster. The details of when APG legislation is enacted and the severity of penalties vary slightly state by state. This thesis will adopt the most common definition of price gouging, which is an increase in prices above pre-emergency levels. For modeling purposes, the pre-emergency prices will in effect be the price ceiling, causing effectively upward price rigidity after the disaster and it is assumed that the penalties are severe enough and enforcement is effective enough that businesses are deterred from breaking the law. Additionally, it is assumed that legislation is in effect from the time of the disaster occurrence and prices do not shift in anticipation of the disaster.

Retailers are not strategically set up for shipments of inventory between stores; therefore there will be cost increases for labor, shipping and the additional risk associated with increasing supplies to a disaster area. If prices remain at their pre-disaster levels, there may be no incentives to redirect supplies. In order for profit driven retailers, wholesalers and distributors to pack up their inventory in stores outside of emergency areas and ship them to the affected area, there must be a financial incentive to do so. The investigation done by the Federal Trade Commission (FTC) into allegations of price gouging after Hurricanes Katrina and Rita found that the increase in gas prices was mainly due to increased costs of 
production and supply in disaster environments (Federal Trade Commission, 2006).

The Federal Trade Commission (FTC) investigation into allegations of price gouging took into account the increased costs of redirecting supplies to a disaster area, but failed to account for the increased costs of responding to volatile demand conditions in a disaster market. Demand management in disaster areas is difficult to predict and there can be significant increases in costs of operation (Wassenhove, 2006 \& Kovacs \& Spens, 2007). Volatile demand patterns lead to increased inventory costs, capacity expenditures and reduced service levels. These operational costs are exacerbated by the implementation of APG legislation, which amplify demand variations through the removal of price fluctuation that serves to smooth demand.

\subsection{Supply CHAin MANAGEMENT AND THE BEER GAME INTRODUCTION}

The purpose of this section is to provide background on the processes that businesses use to manage their supply chains and how these processes and decisions can be modeled. A supply chain is defined by the Association for Operations Management (APICS) as the network used to deliver products and services from raw materials to end customers through an engineered flow of information, physical distribution and capital (Association for Operations Management (APICS), 2008). The traditional supply chain consists of suppliers, producers, distributors and customers. These units are linked through the flow of material downstream and the flow of information upstream with the goal of 
linking supply with demand. In a traditional supply chain, each location is responsible for determining the quantity of goods to order to satisfy their demand independently of other units in the supply chain.

Over the past 20 years, supply chain transaction costs have been reduced dramatically and there has been an increased interest in optimizing how organizations collaborate to improve efficiency (Towill, 1996). This has led to a host of research into the patterns of behavior exhibited by players in supply chains in order to reduce the negative behaviors. The beer game is a common simulation of the dynamic effects of a supply chain. The game is used as a representation of an organization's supply chain in order to model the bullwhip effect.

\section{THE BULLWHIP EFFECT IN THE REAL WORLD}

Significant amplifications in upstream orders, inventory and backlog is a pattern that was first identified in real supply chains. Procter \& Gamble identified the behavior, which is now coined as the "bullwhip" effect, in its consumer goods supply chains. Procter and Gamble realized that although the demand at the retailer for their Pampers baby diaper line was fairly constant, there was a significant increase in the amplification of orders at the wholesaler (Lee, Padmanabhan, \& Whang, 1997). Hewlett Packard saw similar effects when evaluating their printer business. There were small shifts in demand at their retail level, but at the reseller level the swings were amplified and further upstream in their supply chain, in the integrated circuit business, the amplifications in demand were even larger. 


\section{HISTORY OF THE BEER GAME}

The beer game is a simplified representation of a supply chain for generic manufactured goods that replicates the patterns of behavior exhibited in real supply chains. The game has been played by thousands of people, all over the world from high school students to CEOs of major corporations. The beer game serves as a platform to study the dynamic effects that structure and delays can have on a supply chain (Sterman, 1992). The game serves as a useful representation for studying the effects of visibility and delays in information and material flows. The following section has a brief overview of the beer game and the detailed rules for the beer game can be found in Appendix C.

The large swings in demand and amplification in orders cause results in supply chains that are far from optimal because of wasteful overproduction and excess inventory. Despite this, the same patterns in the beer game are exhibited by almost all players, which suggest that all players in that structure use similar heuristics and systematically err in the same manner (Sterman, 1989). The structure of the game causes patterns of behavior, not the cunning of the people who are involved in the decision making.

\section{DESCRIPTION THE BEER GAME}

The beer game is a role playing game that portrays the replenishment and ordering processes used in a supply chain. Beer (commonly root beer in classroom settings) is the generic manufactured good that is produced and distributed through the supply chain. The chain consists of a retailer (R), distributer (D), wholesaler (W) and factory (F). Each segment of the chain places 
orders for beer to satisfy their demand independently without knowledge of the decision making at the other locations in the chain. The retailer, whose goal is to fulfill market customer demand for beer, places orders with the wholesaler in an attempt to maintain their inventory. The wholesaler's customer is the retailer.

The wholesaler tries to maintain their inventory by placing orders with the distributor. Finally, the distributor places orders with the factory. The factory brews the beer and obtains its raw materials from a source that is outside of the scope of the simulation. Figure 4 shows the flow of information and physical goods through the beer supply chain.

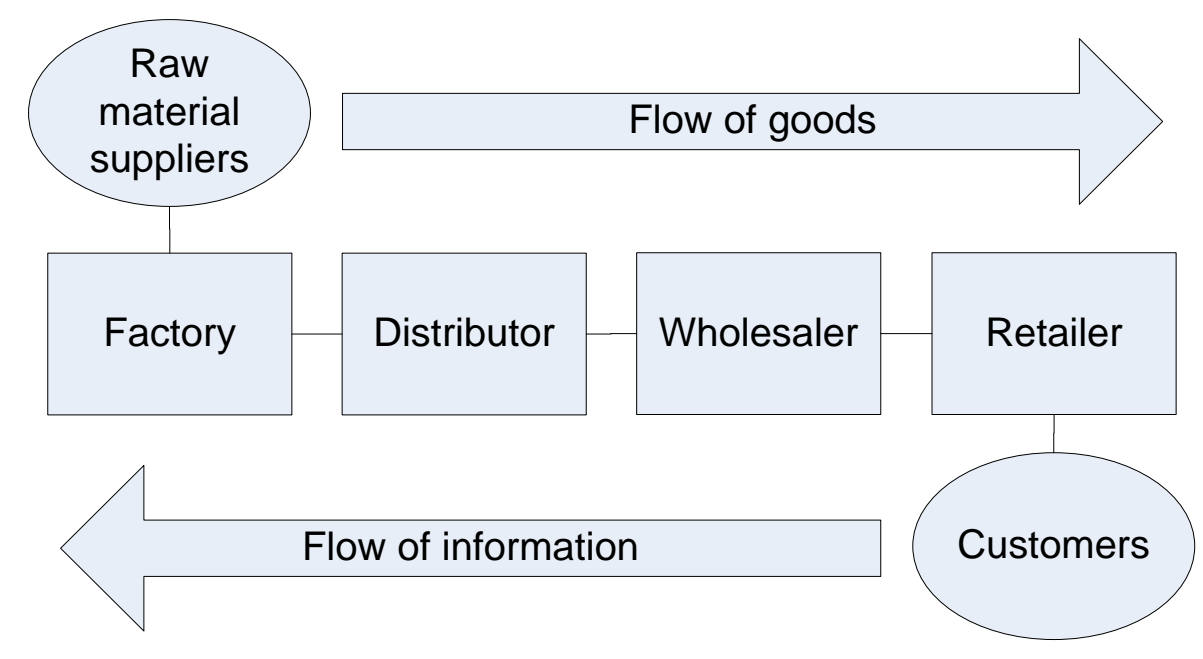

Figure 4 Beer game flow chart

The beer game uses lead times of two weeks (represented as two moves) between an order being placed and an order being received. This simulates the cumulative lead time for processing, packing and shipping of units. Each week, the inventory at each location is depleted by the demand created at a downstream location and the participants in the game attempt to maintain their inventory levels as close to safety stock levels as possible. There are penalty costs of $\$ 0.50$ per 
unit per week of inventory that is held and a penalty cost of $\$ 1.00$ per unit per week of backlog or essentially the inability to meet current demand from a downstream location. The goal of the game is to minimize the penalty costs incurred by maintaining the inventory at the minimum safety stock level while satisfying all of the demand of the next downstream location. The game makes the simplifying assumption of no variation in production times or delays and any capacity or financial constraints.

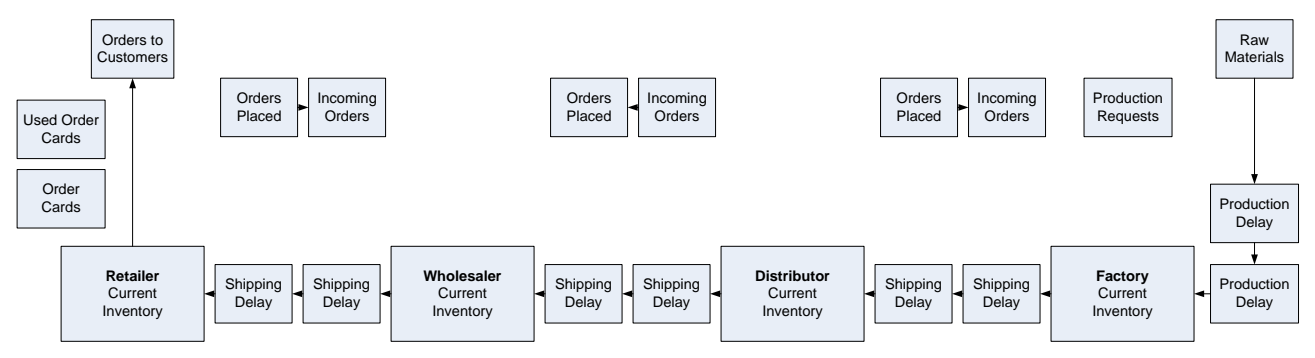

Figure 5 Beer game board

Figure 5 above shows the traditional beer game board. Units of beer move one space per time unit, which represents one week in the game. In the first round, each location in the supply chain acts independently without collaboration or knowledge of what is happening at the locations adjacent to them. This means that each location has no knowledge of the inventories or backlogs of other locations when they are placing their own orders. This is the case in many traditional supply chains. The game starts at time 0 and every simulated week each player makes decisions on how much beer to order. The game is played for a total of 36 weeks or moves.

Participants playing the beer game consistently replicate the common phenomenon of oscillation, phase lag and amplification in inventory levels and 
ordering rates. The beer game shows how ordering decisions within a supply chain systematically diverge from optimum behavior during a demand shift without collaboration (Sterman, 1989).

\section{PATTERNS OF BEHAVIOR IN THE BEER GAME}

Results from thousands of trials of the beer game illustrate common decision making characteristics that cause the system to depart dramatically from optimum behavior. The three common patterns that the beer game reveals are (1) oscillation, (2) amplification and (3) phase lag in orders and inventory levels.

1. Oscillation is the general characteristic of the supply chain system without collaboration. Oscillation in inventory levels and ordering rates around a target value represents instability created by delays in information and shipping. This pattern often causes effective inventory levels that go well into the negative also known as backlog or unfulfilled orders.

2. Amplification is the increase in the peak order rates in each upstream location in the supply chain from retailer to factory. The peak amplitude of orders at the factory can be double the amplitude of the orders at the retailer (McCullen \& Towill, 2002). Sterman has noted that the variance in the orders at the factory can be five times the variance at the retailer (Sterman, 1992).

3. Phase lag is a pattern of behavior characterized by peaks and troughs of the oscillating order rates at one location being out of sync with the peaks and troughs at an adjacent location. 


\section{CAUSES OF THE BULLWHIP EFFECT}

Analysis of the beer game by numerous researchers has identified four major causes of the bullwhip effect (Lee, Padmanabhan, \& Whang, 1997).

- Demand forecast updating: Most businesses use some sort of forecasting method to determine future demand. This method is the heuristic each player uses to project future demand. Orders placed from downstream suppliers are used as a data point to project the upstream supplier's future product demand. Manager's use downstream order signals to readjust their demand forecasts and the orders placed with the suppliers of the upstream operation. When the lead times between order data adjustments are longer, the bullwhip effect is exaggerated.

- Order batching: Orders are often accumulated into batches, which are then passed onto a supplier weekly, bi-weekly or even monthly. Businesses have an incentive not to order too frequently, especially when there is a high time and/or cost associated with order processing. Periodic ordering can increase the variability in order rates, contributing significantly to the bullwhip effect.

- Price fluctuation: Often suppliers will offer promotional pricing in order to reduce unwanted inventory or boost volume in order to meet efficiency goals. Suppliers will periodically have special promotions like price discounts, quantity discounts, coupons, rebates, and so on, which creates forward buying in downstream customers. This causes demand spikes in 
downstream customers that then ripple up through the supply chain causing additional inefficiencies.

- Rationing and shortage gaming: When product demand exceeds supply, a supplier will often ration its product to customers. Customers who suspect a supply shortage will often exaggerate their orders in an attempt to secure the actual desired amount of product in the case of a shortage, creating artificial demand spikes that are exaggerated through the supply chain.

\section{REDUCING THE BULLWHIP EFFECT}

Understanding the causes of the bullwhip effect has led businesses to implement changes to mitigate its effects. In order to reduce the effects of variation through demand forecasting businesses have recognized the need to improve information sharing. Businesses have implemented techniques such as electronic data interchange (EDI) and collaborative forecasting planning and replenishment (CFPR) that allow upstream suppliers to see and match front-end demand. Additionally, because long lead times can aggravate the bullwhip effect, businesses have placed a premium on improving operational efficiency to reduce lead times.

To diminish the effects of order batching on the bullwhip effect, companies have worked to implement systems that reduce the cost of order processing. This allows for more frequent ordering, but does not address the increased transportation costs of increasing the number of orders. To fully address these problems businesses must also reduce the costs associated with transportation of smaller batches. Third party logistics and composite distribution 
channels are used to create varied product mixes for transport allowing for smaller batches to be ordered without increased transport costs.

In order to reduce variations in demand caused by promotional pricing, many businesses have reduced wholesale price discounting in order to eliminate forward buying and diversions. Suppliers use long term collaboration and contracts with customers to establish "everyday low pricing" that keeps demand stable. Additionally, the proliferation of information systems has allowed downstream customers to monitor supply levels more closely. This can reduce fear and forward buying under normal market conditions, although it does not address the problem of fear buying and gaming during a genuine shortage. To address this, suppliers are beginning to create contractual agreements with customers that base rationing on past orders, which eliminates incentives for downstream customers to game the system by over ordering during a shortage (Lee, Padmanabhan, \& Whang, 1997).

\section{DISCUSSION}

The majority of research into the bullwhip effect has examined its causes under normal market conditions. After a disaster there are substantial fears about the availability of critical supplies. This causes customers to engage in forward buying and gaming which are identified as key drivers of the bullwhip effect.

Supply chains in disaster areas have to deal with extremely erratic demand, which has been likened to dealing with "the client from hell" (Arminas, 2005). Businesses cannot establish contractual rationing agreements with frontend customers after a disaster; therefore incentive policies must be developed in order 
to ration products. The most powerful, emergent and well understood of these incentive mechanisms are prices. In times of shortage, retailers can raise prices, which signal a shortage to customers and incentivizes them to be frugal and not to attempt to game the system. Although stable prices create demand stability under normal circumstances, price increases in times of shortage can be used to temper demand with customers where contracts cannot be established. When APG legislation is implemented, this mechanism is removed and the bullwhip effect and its costs are increased.

The beer game is a representation of a business supply chain that mimics the real world behaviors which cause the bullwhip effect. The beer game will be used as a representation of a supply chain to test the effects of APG legislation on the bullwhip effect. The behavior and decision making used in the beer game can be modeled with system dynamics. The equations for modeling the beer game behavior are discussed in the next section.

\subsection{SimUlating THE BEER GAME WITH SYSTEM DYNAMICS}

\section{INTRODUCTION}

In order to model the effects of APG legislation on the bullwhip effect, a simulation of the ordering and replenishment processes of the beer game will be used. Supply chains are complex systems that can create recurring behaviors based on their setup and feedback structures, making them appropriate for analysis through system dynamics. The beer game provides an appropriate platform to test supply chain responses to demand shifts (Ackere, Larsen, \& Morecroft, 1993, Strozzi, Bosch, \& Zaldívar, 2007 \& Joshi, 2000). The system 
dynamics equations and models of the beer game are used to simulate a generic supply chain response to demand shifts.

\section{THE BEER GAME SySTEM DYNAMICS ModeL}

John Sterman from MIT developed a set of equations that mimic the heuristics that each player uses to place orders. Sterman's model is based on data collected from thousands of individuals who have played the beer game. The decision parameters and equations dictating the behavior of the supply chain are given below. The inventory level $\left(I_{t}\right)$ is a function of the incoming orders $\left(i_{t}\right)$ or acquisition rate $\left(A_{t}\right)$, units sold $\left(s_{t}\right)$ or loss rate $\left(L_{t}\right)$ and initial inventory level $\left(I_{0}\right)$. Note that the initial inventory level for the classic beer game is 12 units. The equation for inventory at time $t$ is given by:

$$
I_{t}=\int_{0}^{t}\left(i_{t}-s_{t}\right) d t+I_{0}
$$

Where $I_{t}$ is integrated numerically:

$$
I_{t}=I_{t-1}+i_{t}-s_{t}
$$

The backlog $\left(B_{t}\right)$ is a function of orders placed $\left(o_{t}\right)$ and units sold $\left(s_{t}\right)$ with initial backlog $\left(B_{0}\right)$. Note that the initial backlog for the classic beer game is 0 units. The equation for backlog at time $t$ is given by:

$$
B_{t}=\int_{0}^{t}\left(o_{t}-s_{t}\right) d t+B_{0}
$$

Where $B_{t}$ is integrated numerically:

$$
B_{t}=B_{t-1}+o_{t}-s_{t}
$$


The supply line gap is a function of the orders placed $\left(o_{t}\right)$, the incoming orders and initial supply line gap. Note that the initial supply line gap for the beer game is 0 units.

$$
S L G_{t}=\int_{0}^{t}\left(o_{t}-i_{t}\right) d t+S L G_{0}
$$

Where $S L G_{t}$ is integrated numerically:

$$
S L G_{t}=S L G_{t-1}+o_{t}-i_{t}
$$

The orders placed $\left(o_{t}\right)$ are a function of the indicated order rate $\left(I O_{t}\right)$.

The indicated order rate $\left(I O_{t}\right)$ is a function of the expected losses from stock $\left(s_{t}\right)$, the difference between the desired stock and actual stock $\left(\Delta S_{t}\right)$ and the difference between the desired supply line and the actual supply line $\left(\Delta S L_{t}\right)$.

$$
\begin{gathered}
O_{t}=\max \left(0, I O_{t}\right) \\
I O_{t}=L_{t}+\Delta S_{t}+\Delta S L_{t} \\
L_{t}=x_{1}\left(L_{t-1}\right)+\left(1-x_{1}\right)\left(L_{0}\right) \\
\Delta S_{t}=x_{S}\left(S^{*}-S_{t}\right) \\
\Delta S L_{t}=x_{S L}\left(S L^{*}-S L_{t}\right)
\end{gathered}
$$

Where the weight factors are $x_{1}, x_{S}, x_{S L}$. The desired stock $\left(S^{*}\right)$ are 12 in the standard beer game and the desired supply line $\left(S L^{*}\right)$ is defined by:

$$
S L^{*}=(\text { expected lag })(\text { desired throughput })
$$

An exponential smoothing forecasting method is used by each location in the supply chain to determine the indicated orders $\left(I O_{t}\right)$ for the upstream supplier. 
The method uses historical demand data, which is given progressively less weight in the average as the entry gets older, thus older data has less impact on the average as time increases. The demand forecast for each location is affected by the exponential smoothing weight factors $\mathrm{A}$ and $\mathrm{B}$. The values $\mathrm{A}$ and $\mathrm{B}$ are set to .26 and .088 , respectively.

$$
\left.I O_{t}=\text { Demand forecast (hist smoothing }\right)+A\left(12-E I_{t}\right)-B\left(S L G_{t}\right)
$$

The effective inventory $\left(E I_{t}\right)$ is used to gain insight into the true oscillations within the system. The equation for effective inventory can be seen below.

$$
E I_{t}=I_{t}-B_{t}
$$

The system dynamics simulation of the beer game based on Sterman's equations was developed by Kirkwood at Arizona State University (Kirkwood, 2010). Vensim, system dynamics simulation software, was used to simulate the effects of the beer game. (Ventana Systems, 2010) The demand forecasting heuristic in the simulation is modeled with the SMOOTH function, which is an exponential smoothing calculation. The delays inherent in the system are modeled with the FIXED DELAY function. The equations for the model can be found in Appendix A. 


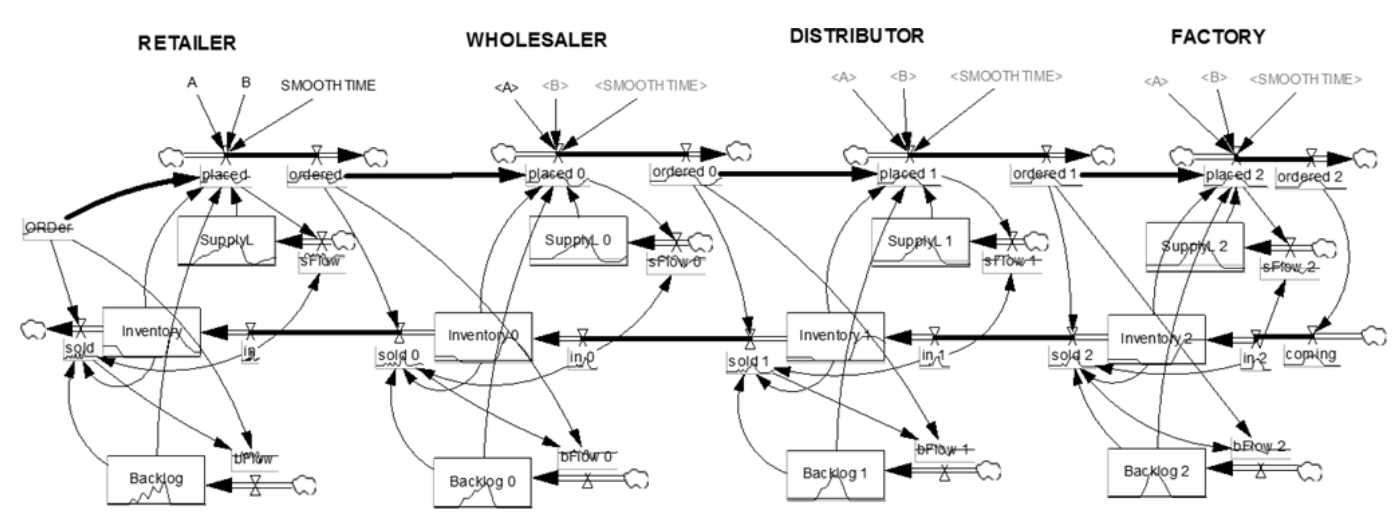

Figure 6 Beer game stock and flow diagram (Kirkwood, 2010)

The model is run for 36 time steps, simulating the standard 36 weeks that are played in the beer game. Each location in the supply chain is made up of replicated processes at each location. Starting from the top left, the ORDer variable is the demand at the retailer. Demand starts at 4 units per week and is increased to 8 units in week 5 using the Vensim STEP function, the same way demand is increased in the beer game. The placed and order rate variables, simulate the ordering heuristic of the location. The demand forecast is created at the placed variable and the delay is imposed at the ordered variable. Each location's ordering heuristic is done independently of one another, without collaboration, the same as the beer game. The supply line (SupplyL), inventory (Inventory) and backlog (Backlog) are modeled as level equations. The supply line accumulation is based on the forecast and determines the rate at which supply line accumulates. The supply outflow equals demand unless there are not enough units in inventory plus incoming units for the week, in which case the orders are accumulate in backlog. 

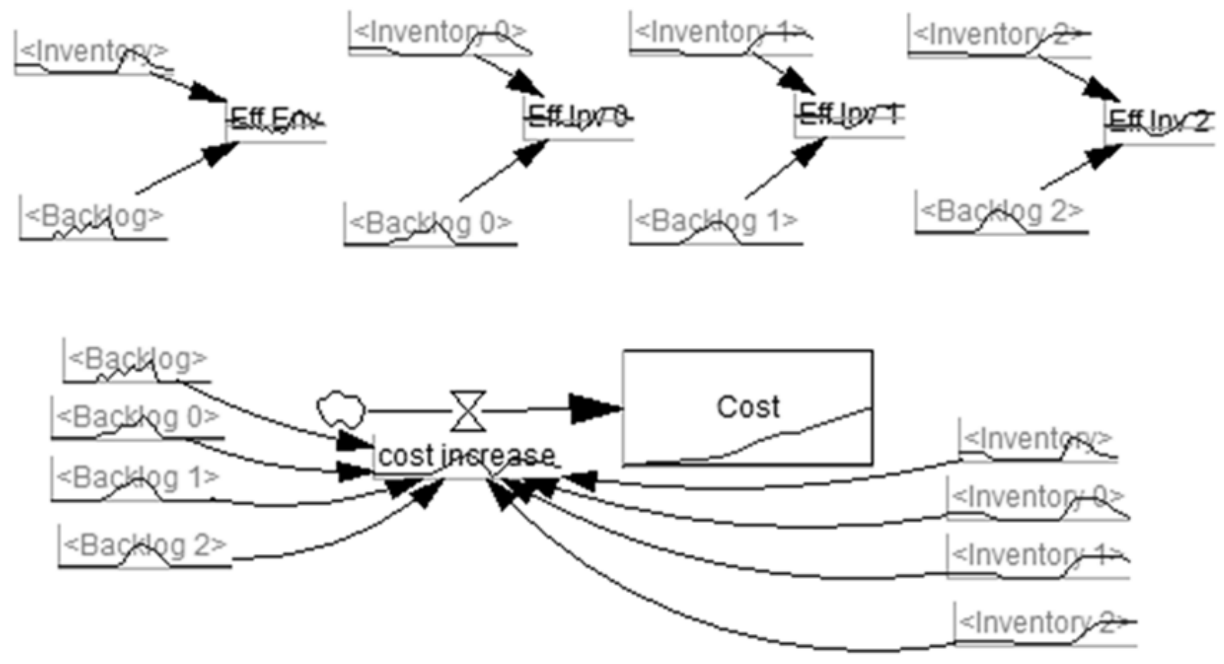

Figure 7 Beer game stock and flow diagram Pg.2 (Kirkwood, 2010)

The effective inventory (inventory - backlog) for each location and the total costs incurred is modeled. The cost is based on the cost penalties incurred in the standard beer game. There is a $\$ 0.50$ cost for each unit of inventory held per week and a $\$ 1.00$ cost for each unit of backlog per week. This allows the costs of changes to be evaluated between test scenarios.

\section{DISCUSSION}

The beer game model simulates the characteristic supply chain patterns of behavior, oscillation, amplification and phase lag, exhibited in the actual beer game. Kirkwood's model of Sterman's equations provides a base model that can be used to test the patterns of behavior and their effects on inventory and backlog costs under different scenarios (Joshi, 2000). The model of the beer game developed by Kirkwood will be used as the base to test the patterns of behavior and performance of a supply chain under APG legislation regulatory scenarios. The input demand patterns will be based off a dynamic demand and price model 
(Whelan \& Msefer, 2003). Front-end demand at the retailer is based off the traditional macroeconomic supply and demand model. This integrated model, discussed in Chapter 4 will be used to test the effects of APG legislation on the bullwhip effect.

\subsection{ECONOMIC ANALYSIS OF ANTI-PRICE GOUGING LEGISLATION}

\section{INTRODUCTION}

This section focuses on applying established macroeconomic analysis of price controls to APG legislation. The model of macroeconomic supply and demand is commonly used by economists to evaluate the effects of price control legislation. Economic work is prevalent in policy research because of the large amount of basic needs which communities rely on everyday and that markets provide. Necessities such as gas, electricity, roofing, hardware, cleaning services and insurance are often completely dependent on "the market" to supply them. After a disaster some of these supplies are supplemented by non-native agencies such as NGOs and state and local governments, but ultimately local businesses will need to return to supplying these goods after the initial response to a disaster.

The principles of economics are built on the fact that resources are limited and scarce and that humans unlimited wants cannot all be satisfied. In its simplest terms, economics is a social science concerned with how to allocate or use limited resources so as to obtain the greatest fulfillment of society's unlimited wants (McConnell \& Brue, 2004). The model state in equilibrium is said to be the most 
efficient ${ }^{1}$ use of resources. The macroeconomic model of supply and demand is often used to illustrate the effects of price controls on supply and demand (Roberts, 2004). The traditional static supply and demand model allows for evaluation of the supply and demand rates under anti-price gouging (APG) legislation.

\section{SUPPLY AND DEMAND MODEL}

The economic model of supply and demand makes three assumptions. The classic supply and demand model assumes (1) a perfectly rational consumer, which means individuals will make choices that are the most beneficial to them. (2) Perfectly competitive markets where no participants are large enough to have the market power to set the price of a given product, and (3) free entry and exit from the market (Hechter \& Kanazawa, 1997). Additionally, this model assumes that all factors other than price, such as changes in taste, income, the price of substitute goods, and the price of complementary goods that affect price are held constant. This is a valid assumption in the short term because changes in price happen on a much smaller time scale than other factors which may affect supply and demand (Hechter \& Kanazawa, 1997).

\section{MACROECONOMIC ANALYSIS OF PRICE CEILINGS}

In a competitive market with limited resources, economists postulate that resources are allocated to their highest value use through consumers tradeoffs

\footnotetext{
${ }^{1}$ Efficient has varying definitions, but economic efficiency refers to the use of resources so as to maximize the production of goods and services given a finite amount of resources. (O'Sullivan \& Sheffrin, 2002)
} 
between goods based on price. A scarcity for a given good or service causes the price to increase and those who have the highest need for the good will be willing to pay the most. The price for the scarce good is bid up until those who do not value it as much reach a price where an alternative is more appealing for the same price. By this mechanism demand is driven down to equal the supply (Roberts, 2004).

In an environment where infrastructure is affected by a disaster, the costs of producing, distributing and selling goods are often increased (Federal Trade Commission, 2006). Additionally, there are increased costs associated with redistributing goods from an intended location to an area of scarcity (Rockoff, 2008). Analysis of price controls during the gas shortages in the 1970s led to the general consensus that they lead to the following consequences (Montgomery, 2007):

- Savings to consumers from lower prices are dissipated by the costs of non-market allocation mechanisms, such as the cost of waiting.

- Shortages are exacerbated because of diminished or eliminated incentives for producers to find replacement supplies and removal of incentives for consumers to ration the remaining supplies.

- Available supplies are not directed to their highest value use, but instead to those who have the lowest costs of waiting.

When disasters such as hurricanes occur, prices can rise due to supply shocks. Prices also rise due to demand increases, as consumers hasten to purchase goods such as gas, generators, hardware and other building materials 
(Davis, 2008). Under APG legislation, when supply shocks occur, the price of a given good is held at the regular market equilibrium point, despite the system shifting into a state of disequilibrium. The effect of this artificial disequilibrium state is that the supply provided is not equal to the amount demanded. The incentive for the market to increase supply to fill the shortage is removed. Figure 8 below shows a static equilibrium model created to show the effects of a price ceiling regulated by APG legislation.
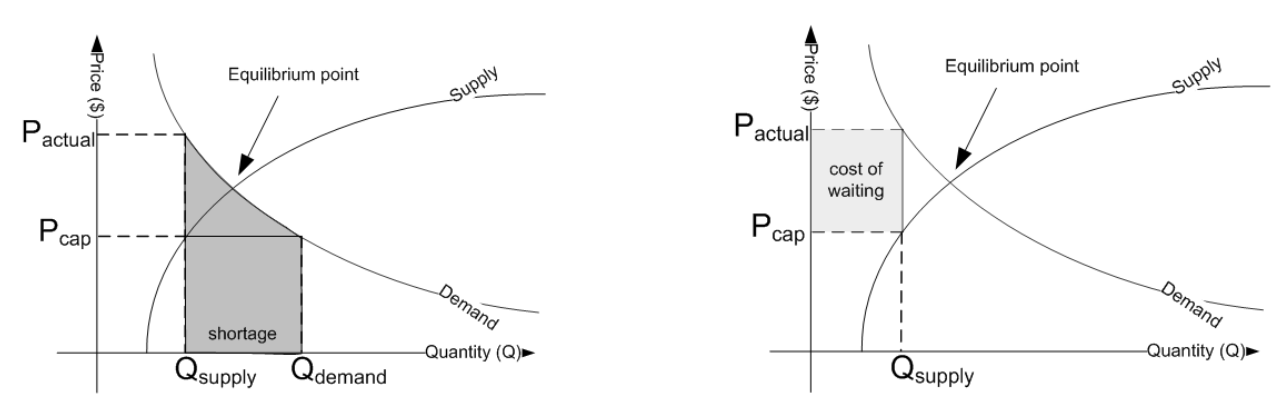

Figure 8 Traditional supply and demand model of price ceilings

Figure 8 above illustrates the supply and demand model under a scenario where a price ceiling $\left(P_{c a p}\right)$ is held below the equilibrium price point after an increase in demand. Under these conditions, the quantity supplied by the market $\left(Q_{\text {supply }}\right)$ is held at the point below what the market would actually like to consume $\left(Q_{\text {demand }}\right)$. The price control therefore creates an artificial shortage that is represented by the area shown under the curve in Figure 8.

$$
P_{\text {actual }}=P_{\text {ceiling }}+C_{\text {waiting }}
$$

A second consequence of the price ceiling is the actual price $\left(P_{\text {actual }}\right)$ of the good is below what the market will bear. Therefore the cost of the good is 
more than the amount that the retailer is actually charging. The actual price under APG legislation is now determined by other market mechanisms, such as the cost of waiting $\left(C_{\text {waiting }}\right)$. Under APG legislation, the actual cost of the good is determined by:

\section{DISCUSSION}

In an environment where there is perfect enforcement of APG legislation, the difference between the price ceiling and the actual price will be determined by the cost of waiting or queuing for the good. When queuing is the sole rationing mechanism, the market clears with money plus waiting time cost (Barzel, 1997). Under APG legislation, each consumer of the good must make a rational decision on the time it will take to receive the good and the value of that good to them.

The traditional model of supply and demand demonstrates the effects of APG legislation on supply and demand incentives. When price ceilings are enacted, some other mechanism of allocating the scarce good will emerges in order to reduce demand to a given supply. Legislators fail to account for APG legislation's effect on private sector incentives to take on the risk of acquiring new lines of supply.

\subsection{SUMMARY}

The purpose of this literature review was to determine an area of disaster management research that would benefit from increased research and to formulate a thesis problem to add that would add to the body of knowledge in this area. The literature review research identified these key issues: 
- Research into disaster recover planning is significantly lacking.

- Anti-price gouging (APG) legislation is a type of state enforced price ceiling that affects business and consumer decision making after a disaster.

- Research into APG legislation effects on local businesses is critical to ensuring local economic recovery from disasters.

- Supply chains in disaster areas have to deal with extremely erratic consumer demand patterns.

- Economic evaluation of price controls evaluates the effects o legislation on consumer and business incentives, but does not address the operational effects of APG legislation.

- The Federal Trade Commission (FTC) investigation into allegations of price gouging did not account for the increased costs of responding to volatile demand conditions in a disaster market.

- During erratic demand patterns, the bullwhip effect significantly amplifies the inventory costs and reduces service levels in a supply chain.

- Modeling of social and political policy issues on businesses is difficult because of their complex nature, nonlinearities and numerous intangibles.

- System dynamics is a flexible simulation framework that can accept the relationships necessary to model in complex legislative and social environments.

- Simulation of supply chain performance and costs can be accomplished using a system dynamics model of the beer game. 
- Modeling of price effects on demand can be accomplished using dynamic economic supply and demand models.

- System dynamics can integrate the models necessary to simulate the feedback loop effects of APG legislation on supply chain dynamics.

Based on the results of the literature review, the author has formulated the formulated the following hypothesis. Anti-price gouging legislation increases businesses' inventory costs, reduces service levels and distorts the need for capacity expansion, which hampers a community's local economic recovery from a disaster. This hypothesis will be tested using a system dynamics model to simulate the market effect on a supply chain under different legislative scenarios. 


\section{CHAPTER 3: Methodology}

The distinction between stocks and flows is well known... Yet economic theories still revolve primarily around flow concepts of supply and demand... [S] tock-variable concepts of supply and demand must be incorporated explicitly in economic models in order to capture the rich disequilibrium behavior characteristics of real socioeconomic systems.

(Mass, 1980)

\section{INTRODUCTION}

Economic analysis of price ceilings applied to APG legislation show the effects on allocation costs and supply shortages stemming from price ceilings, but does not evaluate the operational costs of APG legislation on businesses. The purpose of this thesis is to design a system dynamics model that simulates the effects of APG legislation on the operational costs of demand variation caused by a disaster with and without APG legislation.

In the wake of a disaster, this thesis hypothesizes that prices plays an important role in smoothing demand by creating incentives which reduce forward buying and gaming. Under volatile demand conditions where a shortage is unavoidable, prices adjustments aid in creating demand stability while the supply line capacity adjusts. APG legislation removes price fluctuations that create demand stability, increasing costs for local businesses.

\section{SySTEM DYNAMICS SIMULATION MODEL}

The simulation model for this thesis is designed to model the effects that APG legislation has on supply chain dynamics. System dynamics was chosen as the simulation methodology of choice because of its ability to model and integrate 
both operational, legislative and economic systems. Vensim by Ventana Systems was used as the system dynamics modeling software to simulate the integrated market supply chain model (Ventana Systems, 2010). The integrated market supply chain model simulates the effects of price fluctuations on demand variation and the resulting replenishment dynamics.

The simulation model integrates the system dynamics model of a supply chain based on the beer game with a dynamic economic model of demand and price adjustment. The price model of is based on a dynamic model of supply and demand (Whelan \& Msefer, 2003). The feedback loops in the market portion of the model are based on the causal loop diagram outlined in Figure 9 below.

The casual diagram in Figure 9 shows that as inventory levels drop below the desired safety stock inventory levels, the retailer is incentivized to increase the price of a good to maximize profits. Prices do not adjust immediately, so there is a delay between the desire to increase price and prices actually increasing. As prices increase, the relative value to a market consumer decreases, increasing the appeal of substitute or delayed consumption. This incentive then reduces the front-end demand rate for the retailer. 


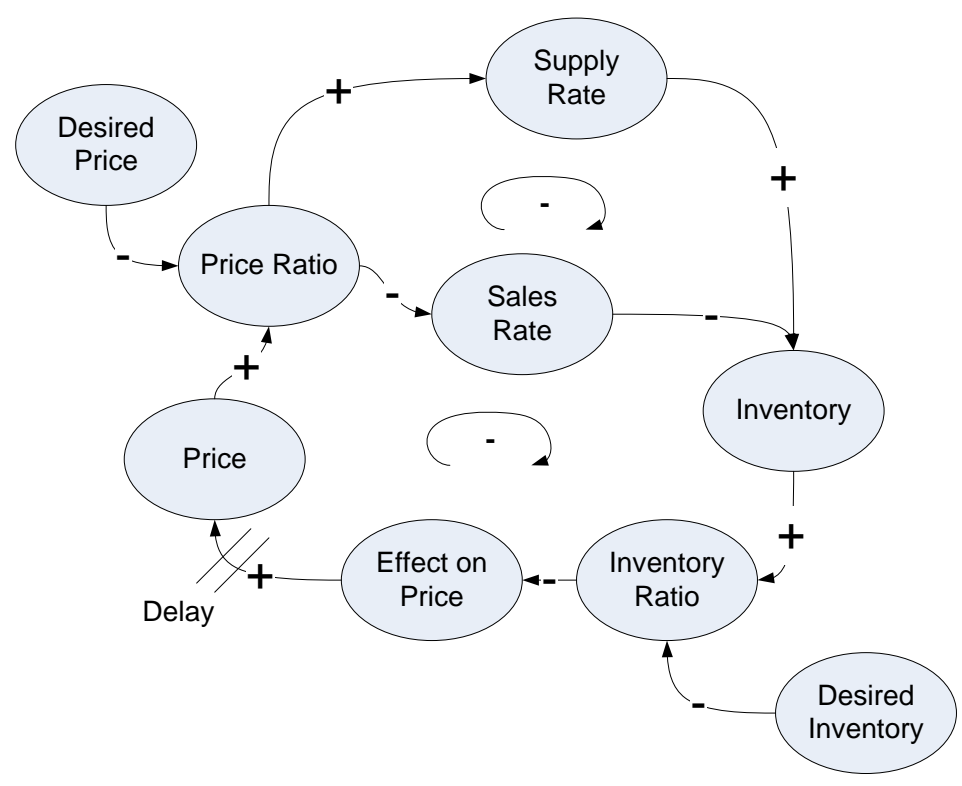

Figure 9 Causal diagram of dynamic supply and demand model

Figure 10 below shows the stock and flow diagram of the simulation model in Vensim. The equations for the model can be found in Appendix A. The sales of the retailer are a function of the demand from the market at a given price point. The inability of the supply chain to supply the goods that are demanded by the market causes the retailer to raise their prices to maintain their desired level of inventory. Conversely, if the retailer inventory level rises above the desired levels, there is a downward pressure placed on the price of the good in order to stimulate market demand and bring the inventory back to the desired safety stock level. These price shifts affect the front-end demand, which is used as the demand input for the supply chain portion of the model. The supply chain portion is designed with Sterman's beer game equations and simulates the results of the beer game under different demand patterns. The supply rate from the beer game 
then feeds back into the market price calculation through the retailer's inventory level relative to their desired inventory.

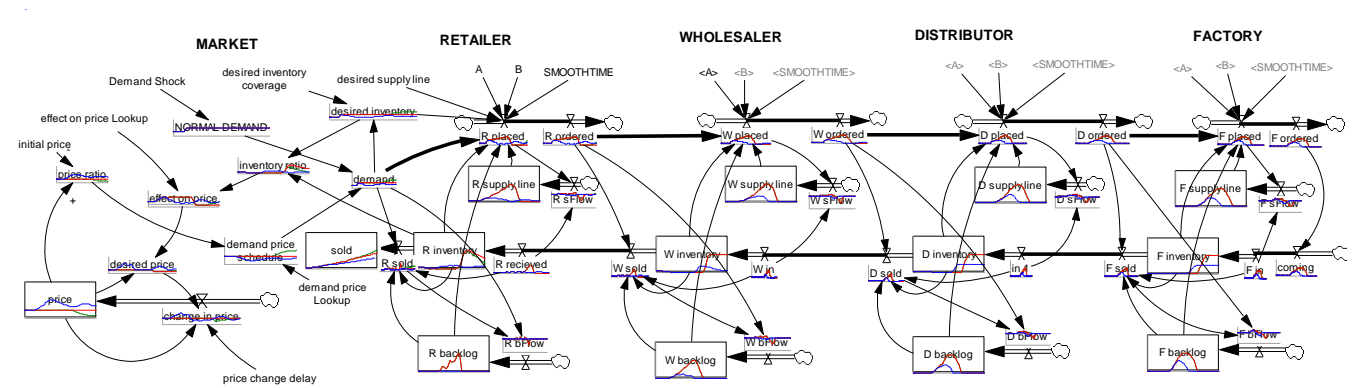

Figure 10 Stock and flow diagram for market integrated supply chain model

\section{METRICS}

In order to evaluate the performance and costs to businesses under different legislative scenarios, the metrics used to evaluate player performance in the beer game are used. The supply chain $\left(C s c_{t}\right)$ costs incurred are measured in the same way as the traditional beer game. The equations used for the model are shown below. The number of units sold to the market from the retailer $\left(U_{t}\right)$ is based on the available retailer inventory, the retailer units received, the market demand and the retailer backlog.

$$
U_{t}=\int_{0}^{t} M I N\left(I_{t}^{R}+r_{t}^{R}, D_{t}+B_{t}^{R}\right) d t
$$

Where $U_{t}$ is integrated numerically:

$$
U_{t}=U_{t-1}+\operatorname{MIN}\left(I_{t}^{R}+r_{t}^{R}, D_{t}+B_{t}^{R}\right)
$$

The total supply chain cost is based on the inventory and backlog costs per unit per week. Where $C_{t}^{S C}$ is integrated numerically: 


$$
C_{t}^{S C}=C_{t-1}^{S C}+(\$ 1.00) \sum B_{t}+(\$ 0.50) \sum I_{t}
$$

The revenue $\left(R_{t}\right)$ of the retailer is based on the price $\left(P_{t}\right)$ of the product and the number of units sold to the market from the retailer $\left(U_{t}\right)$ at time t. Where $R_{t}$ is integrated numerically and the initial price per unit is $\$ 3.33$ :

$$
R_{t}^{R}=R_{t-1}^{R}+P_{t} * U_{t}
$$

The $\operatorname{cost}\left(C_{t}^{R}\right)$ at the retailer is based on the retailer inventory and backlog. Where $C_{t}^{R}$ is integrated numerically:

$$
C_{t}^{R}=C_{t-1}^{R}+(\$ 1.00) B_{t}^{R}+(\$ 0.50) I_{t}^{R}
$$

The results of these metrics along with the patterns of behavior are discussed in the next chapter.

\section{TEST CASES}

Three test scenarios are used in order to simulate the effects of APG legislation on business costs. The following are descriptions of the three test cases:

- Case I: No APG legislation and prices are allowed to be adjusted by the retailer based on the available inventory they have. In Case I, the pricechange delay is set to 12 weeks or one quarter.

- Case II: No price shift allowed in response to inventory. The pricechange delay in Case II is modeled by moving the price-change delay to infinity, therefore creating a model where there is no price shift. 
- Case III: This case is the scenario with APG legislation. APG legislation creates a price ceiling at the initial price for the good. The retailer price can only fluctuate below the initial price.

\section{ASSUMPTIONS}

Modeling of social and legislative environments involves generalization of many complex interactions. This simulation model for this thesis makes some simplifying assumptions in order to simulate the affects of APG legislation. Many of the assumptions are based off behavioral decision theory, rational choice and microeconomics that dictate the behavior of markets, firms and economic systems. The additional assumptions narrow the case in which these results can be held true.

- The model uses a dynamic version of the economic model of supply and demand, which has the following assumptions. (1) A perfectly rational consumer: individuals will make choices that are the most beneficial to them. (2) Perfectly competitive markets: no participants are large enough to have the market power to set the price of a given product. (3) Free entry and exit from the market.

- The simulation model assumes that a retailer is always trying to maximize their profits by charging the highest price possible while maintaining their desired inventory. It is assumed that front-end suppliers do not sacrifice profit margin by discounting in order to sellout their inventory.

Discounting by downstream suppliers is a one of the four key drivers of 
the bullwhip effect, but is not included in the scope of the simulation for this thesis.

- It is assumed that there are only two feedback processes pressuring inventory towards the desired level. The first process is an increase or decrease the quantity ordered at the retailer based on the forecast, which pushes the supply rate toward the demand rate. This creates a net change in the accumulation of inventory. The second process is an increase or decrease in the price at the retailer, changing the demand rate for a product. Combinations of these two strategies are used based on the delays in the feedback loop pressuring change. In the real world there could be additional forces affecting supply and demand rates, but for the purposes of the simulation model for this thesis, they are not included.

- $\quad$ Locations in the supply chain are assumed to always try to minimize their costs on a local level. The assumption is that players attempt to keep their inventories as close to safety stock levels as possible.

- The simulation equations are based off an assumption that the rate at which price and supply rates shift in the upward and downward direction are equal. In reality the upward and downward shifts of price and supply may not be equal. A retailer may be quick to discount inventory when the levels are above a desired level, but more reluctant to raise prices when there are stock outs because of the ill will this may create with customers.

- There is an assumptions that the increase in demand caused by the disaster is only on the regional level and there are no supply and demand 
adjustments based as a result of price at each upstream location in the supply chain.

- It is assumed that a front-end consumer will return to purchase a good at a later time if the product is out of stock. Effectively, there is backlog with front-end market consumers. This may not always be the case. If a product is out of stock, many consumers will not return again to purchase it when stock is returned.

- It is assumed that prices between locations in the supply chain are held constant. This could be through long-term contracts or single source suppliers. By this assumption, the demand rate is based solely on downstream consumers forecast and are not affected by changes in price. 


\section{CHAPTER 4: RESUltS}

The market integrated supply chain model was used to simulate the effects of price fluctuations on a supply chain response to a disaster. The behavior of effective inventory, ordering, price, demand, units sold and financial performance for the retailer (R), wholesaler (W), distributor (D) and factory (F), respectively. For each location the results for each of the three test cases are overlaid on the graph. In each section, analyses of each locations individual results are discussed first followed by an overall evaluation of the patterns of behavior; oscillation, amplification and phase lag.

INVENTORY LEVEL RESULTS

I.

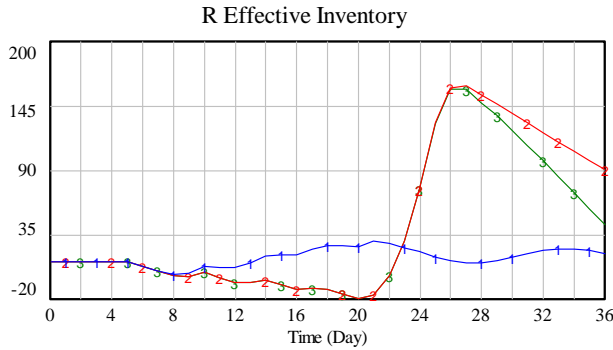

R Effective Inventory : Case I R Effective Inventory : Case III

III.

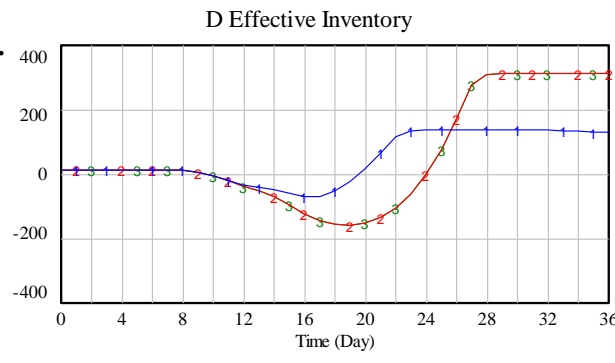

D Effective Inventory : Case I $1,1,1,1,1,1,1$ D Effective Inventory : Case II D Effective Inventory : Case III

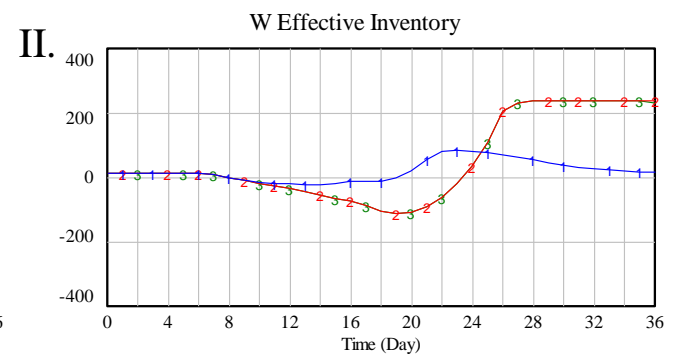

W Effective Inventory : Case I $+, \quad, \quad, \quad, 1,1,1,1$,

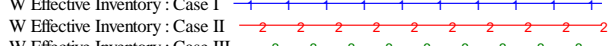
W Effective Inventory : Case III

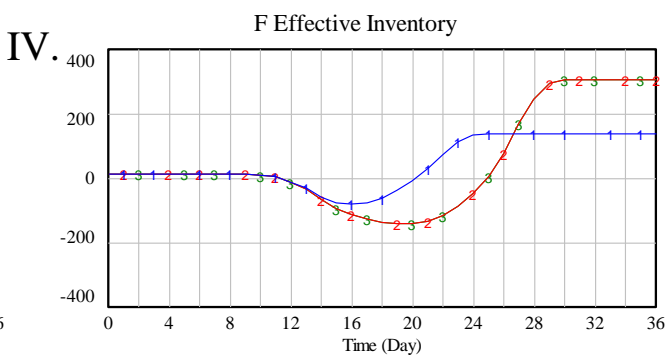

F Effective Inventory : Case I I I l
F Effective Inventory : Case II F Effective Inventory : Case III

Figure 11 Effective inventory levels for Case I, II and III.

The effective inventory is the inventory less the backlog. Anytime the effective inventory is negative for a location, it means that the location has 
backlog. The phase lag in inventory levels can be seen by the peak inventory levels occurring later as one moves from the retailer to factory. Quadrant I of Figure 11 shows the effective inventory results for the retailer location. Note that the scale for this quadrant is from -20 to 200 units compared to the -400 to 400 units in the other three quadrants. The plot of the retailer's inventory shows the large spike in inventory caused by the demand spike at the time of the disaster. It is clear from the scenarios that there is increased variation in inventory levels without price fluctuations. Under APG legislation, the retailer's effective inventory drops to -19 units, compared to 1 unit without APG legislation. The peak inventory under APG legislation is 159 units, compared to 30 units, without APG legislation.

The wholesaler's inventory in Quadrant II of Figure 11 shows the first signs of amplifications in oscillations. The fluctuation at the wholesaler is less pronounced in Case I because of the reduced variation in ordering at the retailer, which can be seen in Quadrant I of Figure 12. Quadrant III shows the inventory for the distributor, which has the highest range (-160 to 312) in inventory levels for Case III. Quadrant IV shows the furthest upstream spike in inventory caused by the demand increase at the retailer. The difference between inventory levels in Case I and III can be clearly seen at the factory location. None of the locations have yet reached steady state equilibrium by the end of the 36 week simulation. The mean, median, minimum, maximum and range for each location in each case can be seen in Table 1 below. 


\begin{tabular}{|llrrrrr|}
\hline Variable & & Mean & Minimum & Median & Maximum & Range \\
R Eff Inv Case I & 15.55 & 1.14 & 15.49 & 29.86 & 28.72 \\
W Eff Inv Case I & 19.28 & -23.94 & 12.00 & 83.03 & 106.97 \\
D Eff Inv Case I & 48.4 & -69.9 & 12.5 & 138.1 & 208.1 \\
F Eff Inv Case I & 46.2 & -81.9 & 13.3 & 139.1 & 221.0 \\
R Eff Inv Case II & 44.2 & -19.4 & 12.0 & 162.3 & 181.8 \\
W Eff Inv Case II & 51.2 & -112.9 & 11.5 & 238.9 & 351.8 \\
D Eff Inv Case II & 57.5 & -158.9 & 12.0 & 312.4 & 471.3 \\
F Eff Inv Case II & 48.8 & -142.5 & 12.0 & 303.7 & 446.2 \\
R Eff Inv Case III & 37.94 & -19.43 & 12.00 & 159.13 & 178.56 \\
W Eff Inv Case III & 51.0 & -112.9 & 11.5 & 238.9 & 351.8 \\
D Eff Inv Case III & 57.5 & -158.9 & 12.0 & 312.4 & 471.3 \\
F Eff Inv Case III & 48.8 & -142.5 & 12.0 & 303.7 & 446.2 \\
\hline
\end{tabular}

Table 1 Effective inventory statistics summary

The effective inventory clearly shows the phase lag in inventory levels between different suppliers. The peak inventory level for the retailer is reached at week 26 and the peak inventory level for the factory is in week 30 . The largest range in effective inventory is 471 units (-159 to 312$)$ at the distributor. The following is an overview of the trends for each individual case:

Case I: The characteristic oscillation and instability are present in this case, but no stock outs occur at the retailer. The bullwhip effect has the least effect in this case because of the leveling effect on demand created through the change in prices.

Case II: The bullwhip effect is very strong in this case. This case has results that are similar to the results of the original beer game, where there are large oscillations and amplifications in inventory levels caused by a demand disruption. Figure 11 shows the bullwhip effect is very pronounced as you move further upstream in the supply chain.

Case III: The bullwhip effect is also very strong in this case, which simulates a market with APG legislation. When backed up orders are received and inventory 
levels rise above desired levels safety stock levels, there is a divergence in behavior between Case II and III in week 26. At this point the price at the retailer is decreased and market demand increases, which can be seen in Figure 14.

\section{ORDER RATE RESULTS}

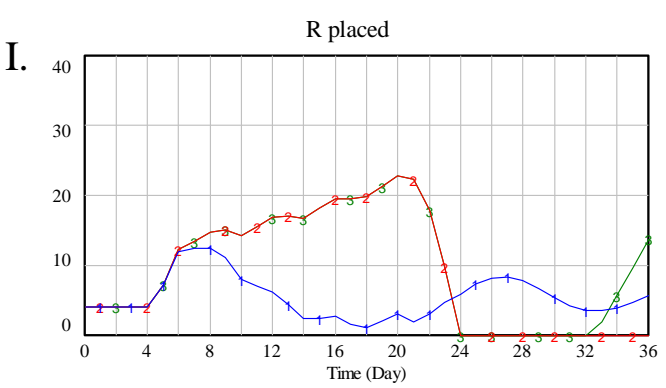

R placed : Case I $\frac{1}{1}+12$
R placed : Case II

III.

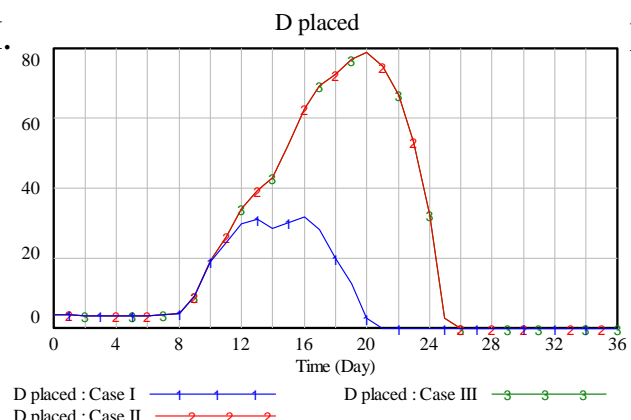

II.

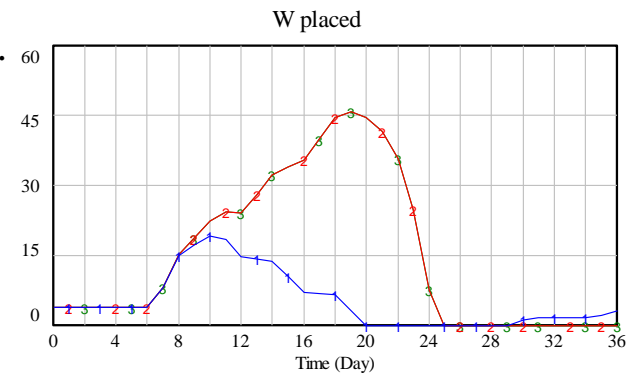

W placed : Case I $\longrightarrow,+$,

W placed : Case III $\quad 3 \quad 3 \quad 3$

IV.

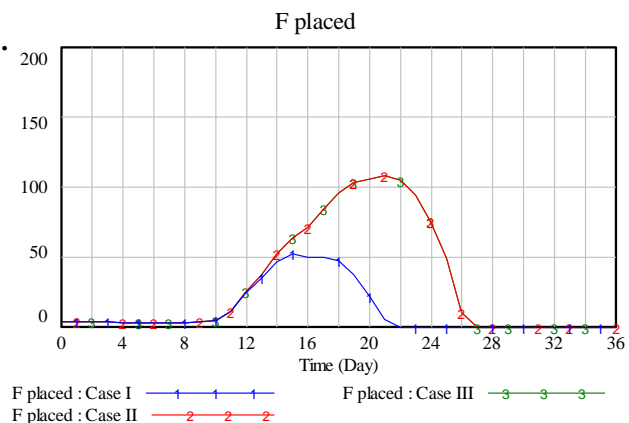

Figure 12 Orders placed at each supply chain location

Figure 12 shows the orders placed rate variable for each location. Note the increasing $y$-axis scale of the plot at each location (0-40 units/week in Quadrant I increasing up to 0-200 units/week in Quadrant IV). The amplification in order rate increases steadily from retailer to factory. The phase lag behavior can be seen by the peak order rate occurring later as one moves from retailer to factory. Quadrant I shows the smoothing effects that price fluctuations have on ordering patterns in Case I. Case II and III show a steadily increasing number of orders per week after the demand spike in week 5, which drops off 
sharply in week 20 once backed up orders finally arrive. This is followed by an 8 week period where there is no ordering. Finally, in week 32 there is a divergence between Case II and II after discounts bring the inventory back below the safety stock level and the retailer begins to place order with the wholesaler again.

Quadrant II shows the first signs of the bullwhip effects as the oscillations in ordering rates at the retailer are amplified at the wholesaler. In Case I, peak order rates of 12 units/week are amplified to17 orders/week. In Case II and III, peak order rates are amplified from 22 units/week at the retailer, to 45 units/week at the wholesaler. This amplification continues at the upstream location, which can be seen in Quadrants III and IV of Figure 12. Quadrant IV, shows the highest amplification in order rate, with a peak of 52 and 108 units per week for Cases I and III, respectively.

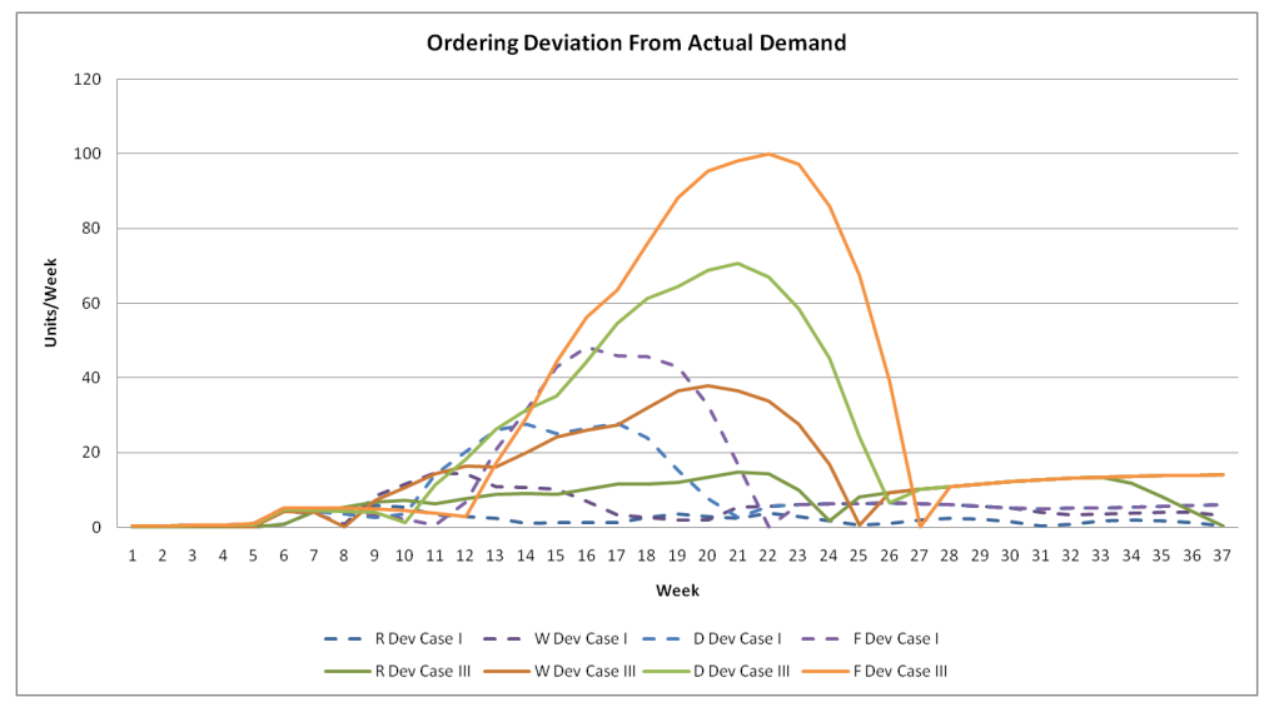

Figure 13 Order absolute deviation from actual demand for Case I and Case III

The orders are placed based on an exponential smoothing forecast of demand. The orders placed at each location in the supply chain all still show the 
characteristic bullwhip behavior, but the with price fluctuations, the bullwhip effect is significantly reduced. Figure 13 above shows the deviations between actual demand and order rates for Case I and Case III. The largest deviations from actual demand occur in Case III, which can be seen in week 22 of Figure 13 above. The deviations from actual demand in Case III are nearly double the deviations in Case I, without APG legislation. The following is a summary of the patterns of behavior in each case.

Case I: The order rates in the supply chain display the characteristic bullwhip behavior, but not to the same extent as Cases II and III. The range in ordering rates at the retailer is 11 units per week ( 1 to 12 ) compared to 48 at the factory ( 3 to 51$)$. This is 4.3 times amplification in ordering rate from retailer to factory. The mean absolute deviation in orders from the actual demand was 1.9, 5.2, 8.9 and 11.0 for the retailer, wholesaler, distributor and factory, respectively.

Case II: The bullwhip effect is again very pronounced in Case II. The ordering rate oscillation range at the retailer is 22 units per week (0 to 22) and 108 at the factory (0 to 108). This is a 5 times amplification in order rate. The mean absolute deviation in orders from the actual demand was 7.3, 13.2, 21.5 and 29.1 for the retailer, wholesaler, distributor and factory, respectively.

Case III: The amplitude of order oscillations increases from retailer to factory. This bullwhip behavior is much more prevalent in this case compared with Case I. The results for this case are similar to Case III until week 32. The order rate at the retailer in week 32 diverges from the Case II level and begins to rise again. The mean absolute deviation in orders from the actual demand was 7.8, 14.7, 22.9 
and 30.3 for the retailer, wholesaler, distributor and factory, respectively. The deviations between actual and perceived demand in Case III are more than double the deviations seen in Case I.

\section{UNITS Sold, PRICE AND DEMAND RESUlts}

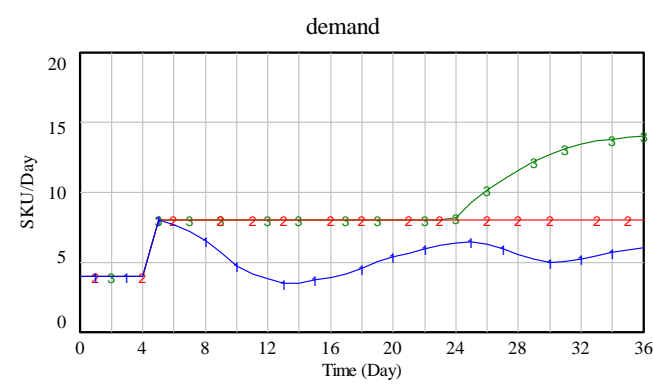

$\begin{array}{lllll}\text { demand : Case I } & 1 & 1 & 1 \\ & \text { demand : Case II } & 2 & 2 & 2\end{array}$

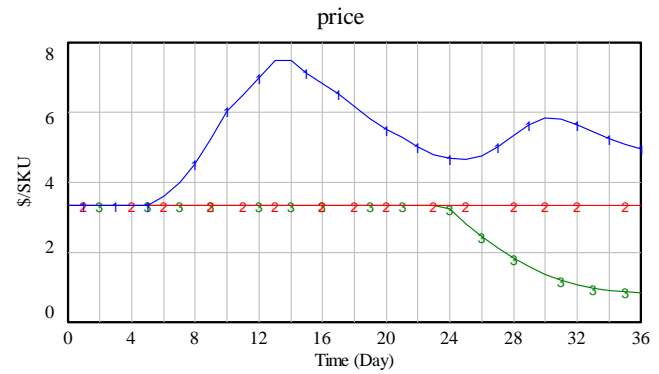

price : Case I $\frac{1}{1}{ }_{1}{ }_{2}+2$
price : Case II

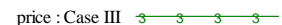

Figure 14 Demand and price results

Figure 14 shows the demand at the retailer on the left and the market price for the goods on the right for Case I, II and III. The demand spike in week 5 simulates the increase in demand for a good after a disaster. In Case I the demand initially spikes, but immediately after, the increase in price begins to reduce demand back to its original levels. Demand in Case III increases again in week 24 as inventory levels rise above the desired safety stock levels and the retailer market price is discounted, which can be seen in Figure 14 to the right. In Case I, the demand is consistently lower than the demand in Case II and III throughout the 36 week simulation. The market price is Case I is consistently higher than the price in Case II and III throughout the 36 week simulation. The following is a summary of the behavior in each case.

Case I: The delay between the demand and price is apparent in Case I. The demand for Case I spikes at the time interval 5 (the time of the disaster), but the 
demand is then reduced because of the increase in price response. The median demand is 5.2 units per week and the minimum is 3.5 units per week. The price has a range of $\$ 4.16$ (\$3.33 to $\$ 7.50)$, a $125 \%$ increase.

Case II \& III: The demand and price response in Case II is the same as Case III until inventory levels rise above the desired safety stock level in week 24 . The price in Case III then rises. Case III has a range of $\$ 2.50$ (\$0.83 to $\$ 3.33)$, a $73 \%$ decrease from pre-emergency price levels.

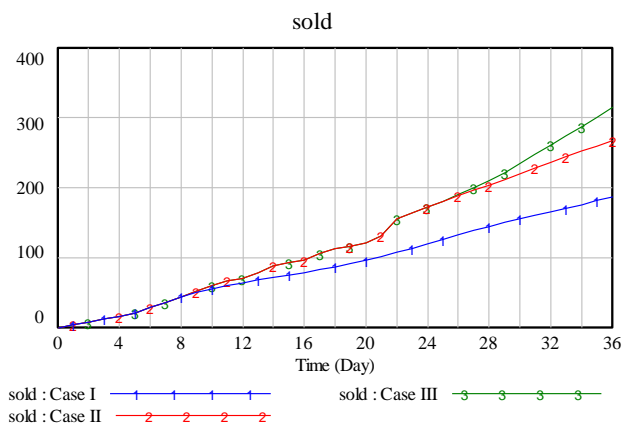

Figure 15 Total units sold at retailer

Figure 15 shows the total number of units sold through the retailer to the market in Cases I, II and III. The retailer has total sales of 182, 260 and 301 units in Case I, II and III, respectively. The cumulative fulfilled market demand is higher when prices are held at pre-emergency levels by APG legislation. The units sold in Case III diverges from Case II, when inventory levels rise above safety stock levels and inventory is discounted, thus increasing demand. In Case I the increased prices during the shortage reduces the demand and holds the cumulative units sold in Cases II and III. The number of units sold in Case II and III is also higher, based on the assumption that front-end consumers will return to purchase the product at a later time if there is a stock out. 


\section{Player Performance Results}
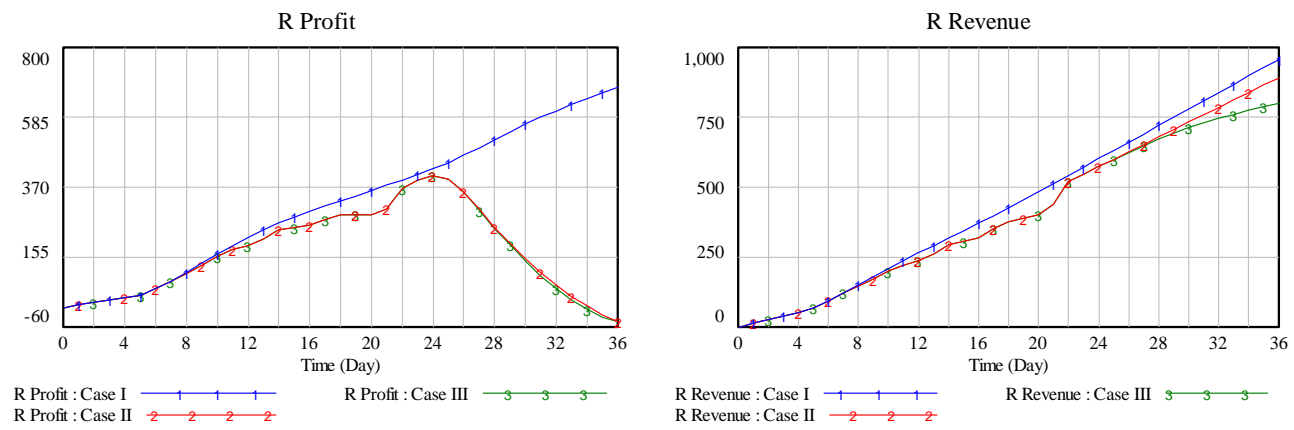

R Revenue : Case III $3 \quad 3 \quad 3$

Figure 16 Retailer profit and revenue

Figure 16 shows the simulated cumulative profit and cumulative revenue at the retailer for Cases I, II and III. The profit for the retailer shown on the right side dips significantly in Case II and III when the inventory levels spike in week 24. In Case I, the profit for the retailer is relatively constant throughout the 36 week simulation.

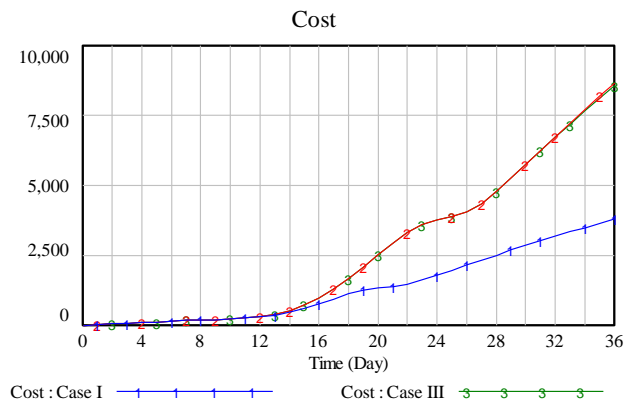

$\begin{array}{lllll}\text { Cost : Case I } & 1 & 1 & 1 & 1 \\ \text { Cost : Case II } & { }_{2} & & & 1\end{array}$

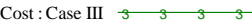

Figure 17 Total supply chain cost

Figure 17 shows the total supply chain inventory and backlog cost for the 36 week simulation. The costs in all three cases is approximately the same for the first 10 weeks of the simulation, but the costs for Case II and III trend steeply upward after week 15. The following is a summary of the performance results of the simulation: 
- The costs for the entire supply chain are $\$ 3,654.00, \$ 8,191.00$ and $\$ 7,690.00$ for Case I, II and III, respectively.

- The revenue for the retailer is $\$ 958.00, \$ 892.00$ and 799.00 for Case I, II, and III, respectively.

- The costs for the retailer are $\$ 297.00, \$ 944.00$ and $\$ 821.00$ for Case I, II and III, respectively.

- The profit for the retailer is $\$ 661.00,-\$ 52.00$ and $-\$ 22.00$ for Case I, II and III, respectively.

\section{DISCUSSION}

As hypothesized, the results of the simulation show increased oscillation, amplification and phase lag associated with the bullwhip effect are more prevalent with APG legislation. The performance results show the deviations from optimal ordering patterns that the increased demand variation under APG legislation propagates. In the simulation, the increase in the price of goods in response to the reduced inventory levels, tempers the demand levels to a sustainable rate of market consumption. The results show that demand is held closer to the supply line rate and inventory levels adjust to their new equilibrium level, thus reducing inventory and backlog costs to the business.

The inventory results in Case I, without legislation, show that the retailer location maintains $100 \%$ service levels. In Case III, with APG legislation, there is a $62 \%$ service level. This means $38 \%$ of the demand from the market is not met under APG legislation. The simulation shows that the leveling of demand created by price fluctuations, maintains positive inventory levels. In a disaster 
environment this means that those who have the greatest need or value for the critical goods will have access to them when needed. Despite the increased prices without APG legislation, there is only a $19 \%$ increase in revenue at the retailer, compared to a $217 \%$ increase in the cost of inventory and backlog for Case II and a $176 \%$ increase for Case III. This rise in cost is dependent on the elasticity ${ }^{2}$ of the demand curve, but based on the assumption that the demand curve is always negative there will always be increased inventory costs with price rigidity.

The simulation results show a $46 \%$ increase in the quantity of goods that are released to the disaster affected region. Although more goods are moved to market with APG legislation, economic analysis presented in the literature review demonstrates that allocation is not based on value to the consumer, but instead goods are awarded to those with the lowest cost of waiting.

Based on the researched costs of the bullwhip effect, removing APG legislation would reduce inventory expenditures and misguided capacity expansion caused by short term demand variance after a disaster. Additionally, the retailer maintains higher service levels, ensuring that critical goods are available through the entire recovery. For these reasons, the non-intuitive practice of allowing prices to fluctuate, which is typically thought to exacerbate the bullwhip effect, allows for demand smoothing that is beneficial to both consumers and businesses.

\footnotetext{
${ }^{2}$ Elasticity refers to the percentage change in quantity demanded in response to a one percent change in price.
} 
The market integrated supply chain simulation results show the increased costs associated with responding to volatile demand variations. The performance results of the simulation show that there are costs associated with removing supplier's ability to respond to supply and demand shocks. Without APG legislation, customers benefit from higher service level rates, and incentives to reduce panic buying and gaming, which create more consistent supply availability. Without APG legislation, businesses benefit from reduced inventory and capacity expenditures. 


\section{CHAPTER 5: CONCLUSION AND FUTURE WORK}

Most important, and most difficult to learn, systems thinking requires understanding that all models are wrong and humility about the limitations of our knowledge. Such humility is essential in creating an environment in which we can learn about the complex systems in which we are embedded and work effectively to create the world we truly desire.

(Sterman, 2002)

\section{CONCLUSION}

The goal of this thesis was to simulate the effects of anti-price gouging (APG) legislation on business supply chains during demand volatility created by a disaster. It was hypothesized that APG legislation increases businesses' inventory costs, reduces service levels and leads to misled capacity expansion, which hampers a community's local economic recovery from a disaster. This thesis contributed to disaster management research for the recovery phase of a disaster, which is the most underrepresented in the current literature. A model based on economic analysis of price ceilings was used to show how price ceilings remove incentives for businesses to increase capacity and distort mechanisms to allocate goods to their most efficient economic use, but did not address the operational effects of APG legislation on businesses.

This thesis focused on APG legislation's contribution to the bullwhip effect by using a soft OR methodology and system dynamics simulation of a supply chain and market response to price fluctuations in a disaster shortage. The system dynamics methodology was well suited to the creation of a dynamic mental model to illustrate the effects of prices on inventory costs and service levels. The system dynamics framework was able to incorporate multiple 
feedback loops necessary to test patterns of behavior in a supply chain model integrated with a dynamic pricing model. The dynamic market simulation, based on the traditional supply and demand, was used to simulate how price shifts can assuage forward buying caused by fear and gaming in the case of a shortage created by a disaster. Forward buying and gaming were identified as the main two of the four key drivers of costs propagated by the bullwhip effect in supply chains after a disaster.

The increased costs associated with demand variation are not accounted for in investigations of price gouging done by the FTC. Increases in prices are attributed solely to costs associated with redistributing of supplies. The results from the system dynamics model created for this thesis show a $176 \%$ increase in inventory and backlog costs under APG legislation after a sudden doubling of demand after a disaster. The increased costs from demand variation after a disaster will put strain on local businesses and their supply chain, retarding the recovery of local economies.

This research has shown that price increases in response to a shortage create incentives for consumers to reduce behavior that causes demand variation when contractual agreements cannot be applied. In addition to reducing incentives for local businesses to increase capacity, the results from the integrated market supply chain model show that APG legislation increases inventory and capacity expenditures and reduce service levels. The conclusion of this thesis coupled with the research into the effects of price ceilings on supply incentives indicate that APG legislation is not an effective regulatory response to decrease 
the impact of disasters on affected communities. For this reason, this author recommends that APG legislation be removed and that government resources be applied to improving public sector aid to reduce the impact of prices on disaster areas.

\section{FUTURE WORK AND CLOSING REMARKS}

This thesis, because of its limited time, focused only the effects of APG legislation on a supply chain behavior, but further research into legislation in disaster environments and disaster recovery planning is needed. Especially critical to focus on for future research is how temporary aid can be used to supplement established supply chains after a disaster. The author believes that a focus on supply management will yield a more effective solution to high prices created by supply shortages, without causing undue stress on local businesses.

The disaster recovery stage is still an area lacking in disaster management research. The effects of government and NGO aid on local economics are areas in need of additional research. Understanding of the tradeoffs between public sector, private sector or hybrid supply lines is needed. Local businesses no doubt play an important role in the long term recovery efforts of a community, but there needs to be a better understanding of their roles and where there can be beneficial collaboration. There must be increased communication between public and private sectors in the development of regulation and policy coordination and the direction of supplies after a disaster. The coordination between public and private sectors can be a tall order because of private sector's view of the public sector being slow and bureaucratic and the public sector's view of the private sector 
being only self-interested (Wassenhove, 2006). There barriers must be overcome to foster coordination between government, NGO and business efforts immediately after a disaster to yield more sustainable and effective results for a community.

The recovery stage is where the contribution of local businesses can have the largest impact on improving humanitarian aid efforts. Understanding how local businesses' established infrastructures and supply chains can be leveraged to come up with long-term efficient recovery efforts is an important area for future research.

Further development modeling business pricing processes are needed. This thesis uses a generalized macroeconomic pricing model, but research into the increased costs for businesses by industry is needed. Markets that are dominated by futures speculation, such as energy resources, will have different price responses to shortages when compared to critical consumer goods markets. For this reason, more detailed pricing models should be developed for particular product types or families.

Lastly, information technology has been identified as a powerful demand management tool. IT systems can not only help reduce the bullwhip effect, but aid in meeting volatile demand more effectively. There is a need for research into how public and private sector information systems can be integrated and leveraged in both supply responses in order to meet critical aid demand. Technology such as EDI has been utilized in supply chains to reduce the bullwhip effect and subdue fears of shortages (Lee, Padmanabhan, \& Whang, 1997). It 
would be beneficial to understand how IT systems could be leveraged to assuage fear of shortages and panic buying after a disaster. Research into how information solutions can be used to communicate demand and supply data and reduce redundant supply activities between public and private sector responses is needed.

This research has provided an operational perspective on one of the effects of APG legislation on supply chain dynamics. This is a first step toward looking more closely at how legislation affects business processes in disaster environments. The majority of legislative analysis is done from a high altitude macroeconomic standpoint and does not account for the effects on processes businesses use to make strategic replenishment decisions. For this reason, the costs of legislation to businesses that play an important role in a community's road to recovery are overlooked. By modeling these effects, an enriched view of the effects of legislation on business performance can be understood and policy decisions can be improved. 


\section{WORKS CITED}

Ackere, A. V., Larsen, E. R., \& Morecroft, J. D. (1993). Systems thinking and business process redesign: An application to the beer game. European Management Journal , 412-423.

Altay, N., \& Green III, W. G. (2006). OR/MS research in disaster operations management. European Journal of Operational Research , 175 (175), 475-493.

Arminas, D. (2005). Supply lessons of tsunami aid. Supply Management, 14. Association for Operations Management (APICS). (2008). APICS Dictionary. Athens, Georgia: APICS.

Barzel, Y. (1997). Economic Analysis of Property Rights (2nd ed.). Cambridge, Massachusetts, USA: Cambridge University Press.

Bryson, K.-M., Millar, H., Joseph, A., \& Mobolurin, A. (2002). Using formal MS/OR modeling to support disaster recovery planning. European Journal of Operations Research, 679-688.

Davis, C. W. (2008, January). An Analysis of the Enactment of Anti-Price Gouging Laws. Retrieved October 7, 2010, from Montana State University Libraries: http://etd.lib.montana.edu/etd/2008/davis/DavisC0508.pdf Federal Trade Commission. (2006, Spring). Federal Trade Commission. Retrieved Novemeber 10, 2010, from The Federal Trade Commission Investigation of Gasoline Price Manipulation and Post-Katrina Gasoline Price Increases: A Commission Report to Congress: 
http://www.ftc.gov/reports/060518PublicGasolinePricesInvestigationReportFinal. pdf

Forrester, J. W. (1961). Industrial Dynamics. Cambridge, Mass: MIT Press.

Forrester, J. W. (1994). System dynamics, systems thinking, and soft OR. System Dynamics Review , 245-256.

Hechter, M., \& Kanazawa, S. (1997). Sociological Rational Choice Theory. Annual Review of Sociology , 191-214.

Joshi, Y. V. (2000). Information Visibility in Supply Chains. Massachusetts Institute of Technology.

Kirkwood, C. (2010, May 5). Business Process Analysis Workshops: System Dynamics Models. Retrieved October 1, 2010, from Arizona State University: Department of Management: http://www.public.asu.edu/ kirkwood/sysdyn/SDWork/SDWork.htm Kovacs, G., \& Spens, K. M. (2007). Humanitarian logistics in disaster relief operations. International Journal of Physical Distribution \& Logistics Management, 99-114.

Lancaster University - Management School. (2010). What is Management Science. Retrieved September 3, 2010, from http://www.lums.lancs.ac.uk/departments/ManSci/DeptProfile/WhatisManSci/ Lee, H. L., Padmanabhan, V., \& Whang, S. (1997). The Bullwhip Effect in Supply Chains. Sloan Management Review , 93-102. 
Mass, N. J. (1980). Destabilizing impacts of price and quantity adjustments to relative supply and demand. Journal of Economic Behavior \& Organization, 97.

McConnell, C. R., \& Brue, S. R. (2004). Economics: Principles, Problems, and Policies. Benicia, CA: Irwin/McGraw-Hill.

McCullen, P., \& Towill, D. (2002). Diagnosis and Reduction of Bullwhip Effect in Supply Chains. Supply Chain Management: An International Journal , 164179.

Mingers, J., \& Resenhead, J. (2004). Problem structuring methods in action. European Journal of Operations Research , 530-554.

Montgomery, D. (2007, April 10). Potential Effects of Proposed Price Gouging Legislation on Cost and Severity of Supply Interuptions. Retrieved October 10, 2010, from American Council for Capital Formation: http://www.accf.org/media/dynamic/3/media_36.pdf

O'Sullivan, A., \& Sheffrin, S. M. (2002). Economics: Principles in Action. Upper Saddle River, New Jersey: Pearson Prentice Hall.

Quarantelli, E. L. (1986). Disaster Crisis Management. Deleware: University of Delaware.

Quarantelli, E. L. (1988). Disaster Crisis Management: A Summary of Research Findings. Journal of Management Studies, 373-385.

Quarantelli, E. L. (1998). What is a Disaster?: A Dozen Perspectives on the Question. Benton, California: Routledge. 
Roberts, R. (2004). Applications of Supply and Demand. Chicago: George Mason University.

Rockoff, H. (1984). Drastic Measures: A History of Wage and Price Controls in the United States. Cambridge, Massachusettes: Cambridge University Press.

Rockoff, H. (2008). The Concise Encyclopedia of Economics. Retrieved

November 13, 2010, from The Library of Economics and Liberty:

<http://www.econlib.org/library/Enc/PriceControls.html>

Scholtes, P. R. (1998). The Leader's Handbook. New York: McGraw-Hill.

Senge, P. M. (1990). The Fifth Discipline. New York: DoubleDay.

Sterman, J. D. (2002). All models are wrong: reflections on becoming a systems scientist. System Dynamics Review , 501-531.

Sterman, J. D. (1989). Misperceptions of feedback in dynamic decision making. Organizational Behavior and Human Decision Processes, 301-335.

Sterman, J. D. (1992). Teaching Takes Off: Managerial Simulation: "The Beer Game". OR/MS Today , 40-44.

Strozzi, F., Bosch, J., \& Zaldívar, J. (2007). Beer game order policy optimization under changing customer demand. Decision Support Systems , 2153-2163.

Towill, D. R. (1996). Industrial Dynamics Modeling of Supply Chains. International Journal of Physical Distribution \& Logistics Management, 23-43. Ventana Systems. (2010, November). Vensim from Ventana Systems. Retrieved November 21, 2010, from http://www.vensim.com/venple.html 
Wassenhove, L. V. (2006). Humanitarian Aid Logistics: supply chain management in high gear. Journal of Operational Research Society , 475-489.

Whelan, J., \& Msefer, K. (2003, August 12). MIT System Dynamics in Education

Project. Retrieved October 5, 2010, from Economic Supply and Demand:

http://sysdyn.clexchange.org/sdep/Roadmaps/RM6/D-4388.pdf

Winston, W. L. (1997). Operations Research: Applications and Algorithms.

Belmont, California: Wadsworth Publishing Company. 


\section{APPENDIX A}

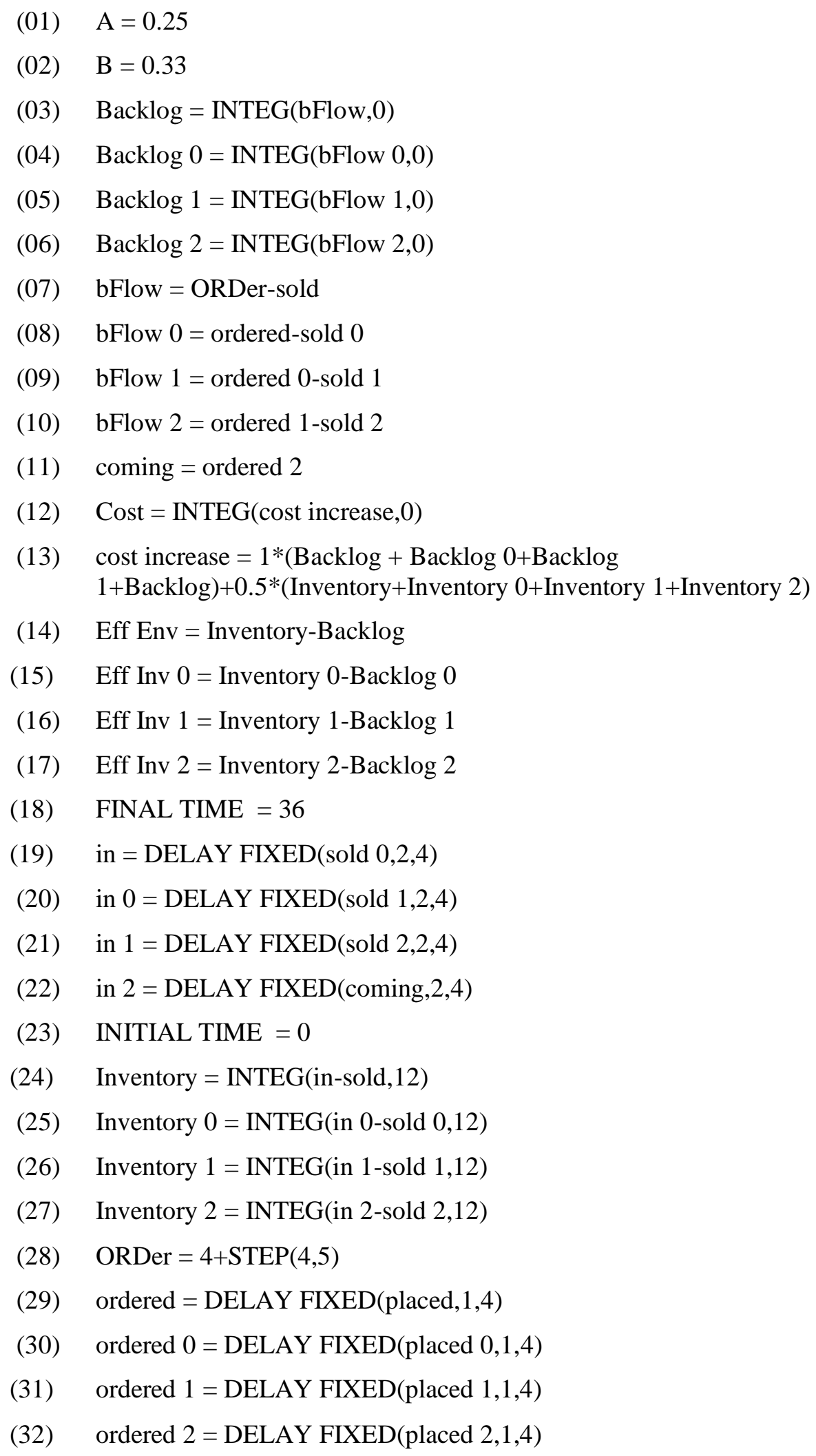


(33) $\quad$ placed $=$ MAX $(0$, SMOOTH(ORDer,SMOOTHTIME) + A*(12-(InventoryBacklog)-B*SupplyL))

(34) placed $0=$ MAX $(0, S M O O T H($ ordered,SMOOTHTIME) $+\mathrm{A} *(12$-(Inventory 0Backlog 0)-B*SupplyL 0))

(35) placed $1=$ MAX $(0$, SMOOTH(ordered 0,SMOOTHTIME)+A*(12-(Inventory 1Backlog 1)-B*SupplyL $1 \quad$ ))

(36) placed $2=$ MAX $(0$, SMOOTH(ordered 1,SMOOTHTIME)+A*(12-(Inventory 2Backlog 2)-B*SupplyL $2 \quad$ ))

(37) SAVEPER = TIME STEP

(38) $\quad$ sFlow $=$ placed - in

(39) sFlow $0=$ placed 0 -in 0

(40) sFlow $1=$ placed 1 -in 1

(41) sFlow $2=$ placed 2-in 2

(42) SMOOTHTIME $=1$

(43) $\quad$ sold $=$ MIN (Inventory+in, ORDer+Backlog)

(44) sold $0=\operatorname{MIN}($ Inventory $0+$ in 0 ,ordered + Backlog 0 )

(45) sold $1=$ MIN(Inventory 1+in 1, ordered 0+Backlog 1)

(46) sold $2=$ MIN(Inventory 2+in 2, ordered 1+Backlog 2)

(47) SupplyL = INTEG $($ sFlow, 0$)$

(48) SupplyL $0=$ INTEG(sFlow 0,0$)$

(49) SupplyL 1 = INTEG(sFlow 1,0)

(50) SupplyL 2 = INTEG(sFlow 2,0)

(51) TIME STEP $=1$

Table 2 Vensim equations for beer game model (Kirkwood) 
(01) $\quad \mathrm{A}=0.26$

Forecast parameter

(02) $\mathrm{B}=0.088$

\section{Forecast parameter}

(03) $\quad$ change in price $=($ desired price-price $) /$ price change delay

Change in price can be positive or negative. If effect on price is $>1$ then price will increase. If effect on price $<1$ the price will decrease. If effect on price $=1$ then the price remains the same. The price change delay models the rate at which price changes

(04) $\quad$ coming $=$ F ordered

Materials that are in transit to the factory

(05) $\quad$ Cost $=$ INTEG $($ cost increase, 0$)$

The cost for the entire supply chain as a result of the inventory and backlog costs

(06) $\operatorname{cost}$ increase $=1 *(\mathrm{R}$ backlog $+\mathrm{W}$ backlog $+\mathrm{D}$ backlog $+\mathrm{F}$ backlog $)+0.5 *(\mathrm{R}$ inventory $+\mathrm{W}$ inventory $+\mathrm{D}$ inventory $+\mathrm{F}$ inventory)

The weekly cost for the entire supply chain

(07) D backlog $=$ INTEG(D bFlow,0)

The backlog for the distributor

(08) $\quad$ D bFlow $=\mathrm{W}$ ordered-D sold

The accumulation of backlog at the distributor

(09) D Effective Inventory = D inventory-D backlog

The effective inventory (inventory - backlog) of the distributor

(10) D inventory= INTEG (in 1-D sold, desired inventory)

The inventory at the distributor

(11) D ordered = DELAY FIXED $($ D placed $, 1,4)$

Orders that have been placed the distributor that are in transit

(12) D placed $=$ MAX $(0, \operatorname{SMOOTH}(\mathrm{W}$ ordered,SMOOTHTIME $)+\mathrm{A} *(12-(\mathrm{D}$ inventory-D backlog)-B*D supply line))

Orders placed by the distributor

(13) D sFlow $=$ D placed-in 1

The supply line accumulation at the distributor

(14) D sold $=$ MIN(D inventory+in 1, W ordered $+\mathrm{D}$ backlog)

Units sold by the distributor

(15) D supply line= INTEG (D sFlow, desired supply line)

Supply line for the distributor 
(16) demand=demand price schedule*NORMAL DEMAND

The weekly demand from the market for a certain good

(17) demand price Lookup([(0,0)-(4,2)],(0,2),(1,1),(2,0.5),(3,0.25),(4,0.2))

Based on the demand curve. At some price $(P)$, the consumers are willing and have the ability to purchase a unit at a certain rate. The lower the price; the higher the demand and vice versa.

(18) demand price schedule $=$ demand price Lookup(price ratio)

(19) Demand Shock=4

The amount that demand increases at the time of the disaster

(20) desired inventory $=$ demand $*$ desired inventory coverage

The inventory that the retailer wishes to carry

(21) desired inventory coverage $=3$

The number of weeks the retailer wants their inventory to cover

(22) Case I \& II: desired price=effect on price* ${ }^{*}$ price

Case III: $\quad$ IF THEN ELSE(effect on price* ${ }^{*}$ price $<$ price, effect on price*price, price)

The price the retailer would like to charge at the current time based on current inventory levels

(23) desired supply line $=12$

The desired supply line

(24) effect on price=effect on price Lookup(inventory ratio)

This effect regulates price change. When inventory > desired inventory then the ratio is $>1$ and the price is reduced. If the inventory < desired inventory then the ratio is $<1$ and the price is increased.

(25) effect on price Lookup( $[(0,0)-(3,3)],(-$ $1,4),(0,3),(0.1,2.8),(0.2,2.6),(0.3,2.4),(0.4,2.2),(0.5,2),(0.6,1.8),(0.7,1.55),(0.8,1.3$ $5),(0.9,1.15),(1,1),(1.1,0.85),(1.2,0.75),(1.2,0.75),(1.3,0.65),(1.4,0.55),(1.5,0.5),($ $1.6,0.45),(1.7,0.4),(1.8,0.35),(1.9,0.3),(2,0.25),(2.1,0.2),(2.2,0.15),(2.3,0.1),(2.4,0$ $.05),(2.5,0),(3,-0.6))$

(26) $\quad$ F backlog $=$ INTEG $($ F bFlow, 0$)$

The backlog for the factory

(27) $\quad$ F bFlow $=$ D ordered-F sold

The backlog accumulation for the factory

(28) F Effective Inventory $=\mathrm{F}$ inventory-F backlog

The effective inventory (inventory - backlog) of the factory

(29) $\quad$ F in = DELAY FIXED $($ coming, 2,4$)$ 
The incoming orders for the factory

(30) F inventory= INTEG (F in-F sold,desired inventory)

The inventory at the factory

(31) F ordered = DELAY FIXED $($ F placed $, 1,4)$

Orders that have been placed at the factory that are in transit

(32) $\quad$ F placed $=$ MAX $(0$, SMOOTH(D ordered,SMOOTHTIME) + A $*(12-(\mathrm{F}$ inventory-F backlog)-B*F supply line))

Orders placed by the factory

(33) $\quad$ F sFlow $=$ F placed $-F$ in

The supply line accumulation at the factory

(34) $\quad \mathrm{F}$ sold $=\mathrm{MIN}(\mathrm{F}$ inventory $+\mathrm{F}$ in, $\mathrm{D}$ ordered $+\mathrm{F}$ backlog $)$

Units sold by the factory

(35) F supply line= INTEG ( F sFlow,desired supply line)

Supply line for the factory

(36) FINAL TIME $=36$

(37) in $1=$ DELAY FIXED $($ F sold, 2,4$)$

(38) initial price $=3.33$

(39) INITIAL TIME $=0$

(40) inventory ratio $=\mathrm{R}$ inventory/desired inventory

(41) NORMAL DEMAND= 4+ STEP(Demand Shock,5)

(42) price $=$ INTEG ( change in price, initial price)

(43) Case I \& III: $\quad$ price change delay $=12$

Case II: $\quad$ price change delay=2E6

(44) $\quad$ price ratio $=$ price/initial price

(45) profit increase $=$ price $* \mathrm{R}$ sold $-0.5 * \mathrm{R}$ inventory $-1 * \mathrm{R}$ backlog

(46) $\mathrm{R}$ backlog $=$ INTEG $(\mathrm{R}$ bFlow, 0$)$

The backlog for the retailer

(47) R bFlow = demand-R sold

The accumulation of backlog at the retailer

(48) R Effective Inventory $=\mathrm{R}$ inventory-R backlog

The effective inventory (inventory - backlog) of the retailer

(49) R inventory = INTEG ( $\mathrm{R}$ received-R sold,desired inventory)

The inventory at the retailer

(50) $\mathrm{R}$ ordered $=$ DELAY FIXED $(\mathrm{R}$ placed $, 1,4)$ 
Orders that have been placed at the retailer that are in transit

(51) R placed=MAX $\left(0, S M O O T H\left(\right.\right.$ demand,SMOOTHTIME) $+\mathrm{A}^{*}$ (desired inventory( $\mathrm{R}$ inventory- $\mathrm{R}$ backlog)-B*(desired supply line- $\mathrm{R}$ supply line)))

Orders placed by the retailer

(52) R Profit= INTEG (profit increase,0)

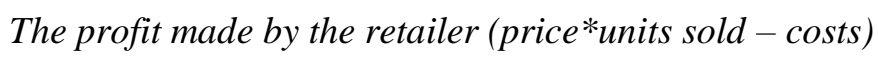

(53) $\quad \mathrm{R}$ received $=$ DELAY FIXED $(\mathrm{W}$ sold $, 2,4)$

The orders received by the retailer

(54) $\quad \mathrm{R}$ sFlow $=\mathrm{R}$ placed $\mathrm{R}$ received

The supply line accumulation at the retailer

(55) $\mathrm{R}$ sold $=\mathrm{MIN}(\mathrm{R}$ inventory $+\mathrm{R}$ received,demand $+\mathrm{R}$ backlog)

Units sold by the retailer

(56) R supply line= INTEG ( R sFlow,desired supply line)

Supply line for the retailer

(57) SAVEPER = TIME STEP

(58) SMOOTHTIME $=1$

Forecasting parameter

(59) sold= INTEG (R sold,0)

The cumulative number of units consumed by the market

(60) TIME STEP $=1$

Modeling parameter

(61) W backlog = INTEG $(\mathrm{W}$ bFlow, 0$)$

The backlog for the warehouse

(62) $\quad \mathrm{W}$ bFlow $=\mathrm{R}$ ordered-W sold

The accumulation of backlog at the warehouse

(63) W Effective Inventory $=\mathrm{W}$ inventory-W backlog

The effective inventory (inventory - backlog) of the warehouse

(64) $\mathrm{W}$ in = DELAY FIXED $(\mathrm{D}$ sold $, 2,4)$

Incoming orders at the warehouse

(65) W inventory= INTEG (W in-W sold,desired inventory)

The inventory at the warehouse

(66) $\mathrm{W}$ ordered = DELAY FIXED $(\mathrm{W}$ placed,1,4)

Orders that have been placed at the warehouse that are in transit

(67) W placed $=$ MAX $(0, S M O O T H(R$ ordered,SMOOTHTIME) $+\mathrm{A} *(12-(\mathrm{W}$ inventory-W backlog)-B*W supply line)) 


\section{Orders placed by the warehouse}

(68) $\quad \mathrm{W}$ sFlow $=\mathrm{W}$ placed $-\mathrm{W}$ in

The supply line accumulation at the warehouse

(69) $\quad \mathrm{W}$ sold $=\mathrm{MIN}(\mathrm{W}$ inventory $+\mathrm{W}$ in, $\mathrm{R}$ ordered $+\mathrm{W}$ backlog $)$

Units sold by the warehouse

(70) W supply line= INTEG (W sFlow,desired supply line $)$

Supply line for the warehouse

Table 3 Vensim equations for the integrated supply chain model 
Maynard: The Effects of Anti-Price Gouging Legislation on Supply Chain Dynamics

\section{APPENDIX B}

\begin{tabular}{|c|c|c|c|c|}
\hline Time (Week) & R Eff Inv Case I & W Eff Inv Case I & D Eff Inv Case I & F Eff Inv Case I \\
\hline 0.0 & 12.0 & 12.0 & 12.0 & 12.0 \\
\hline 1.0 & 12.0 & 12.0 & 12.0 & 12.0 \\
\hline 2.0 & 12.0 & 12.0 & 12.3 & 12.3 \\
\hline 3.0 & 12.0 & 12.0 & 12.5 & 12.5 \\
\hline 4.0 & 12.0 & 11.7 & 12.5 & 12.9 \\
\hline 5.0 & 12.0 & 11.5 & 12.5 & 13.3 \\
\hline 6.0 & 8.0 & 11.2 & 12.1 & 13.3 \\
\hline 7.0 & 4.3 & 7.8 & 11.6 & 13.3 \\
\hline 8.0 & 1.1 & -0.3 & 11.0 & 12.6 \\
\hline 9.0 & 1.7 & -8.9 & 6.4 & 11.7 \\
\hline 10.0 & 7.6 & -17.4 & -4.9 & 10.5 \\
\hline 11.0 & 6.8 & -20.6 & -18.3 & 4.2 \\
\hline 12.0 & 6.5 & -18.6 & -33.5 & -11.4 \\
\hline 13.0 & 10.7 & -21.7 & -42.8 & -32.1 \\
\hline 14.0 & 17.1 & -23.9 & -50.0 & -57.8 \\
\hline 15.0 & 17.4 & -19.2 & -60.4 & -77.9 \\
\hline 16.0 & 17.6 & -14.1 & -69.9 & -81.9 \\
\hline 17.0 & 22.9 & -12.9 & -69.6 & -77.1 \\
\hline 18.0 & 26.1 & -11.4 & -52.3 & -62.3 \\
\hline 19.0 & 25.2 & -2.0 & -24.1 & -38.3 \\
\hline 20.0 & 24.3 & 21.3 & 15.7 & -8.4 \\
\hline 21.0 & 29.9 & 54.1 & 64.5 & 28.9 \\
\hline 22.0 & 27.4 & 81.8 & 114.3 & 73.5 \\
\hline 23.0 & 23.5 & 83.0 & 135.3 & 111.2 \\
\hline 24.0 & 20.3 & 80.0 & 138.1 & 133.3 \\
\hline 25.0 & 15.8 & 75.3 & 138.1 & 139.1 \\
\hline 26.0 & 12.4 & 69.4 & 138.1 & 139.1 \\
\hline 27.0 & 10.8 & 62.1 & 138.1 & 139.1 \\
\hline 28.0 & 10.7 & 53.9 & 138.1 & 139.1 \\
\hline 29.0 & 12.5 & 45.5 & 138.1 & 139.1 \\
\hline 30.0 & 15.5 & 37.7 & 138.1 & 139.1 \\
\hline 31.0 & 18.8 & 31.1 & 138.1 & 139.1 \\
\hline 32.0 & 21.6 & 25.8 & 137.0 & 139.1 \\
\hline 33.0 & 23.1 & 21.6 & 135.3 & 139.1 \\
\hline 34.0 & 22.9 & 19.1 & 133.7 & 139.1 \\
\hline 35.0 & 21.5 & 17.3 & 132.0 & 139.1 \\
\hline 36.0 & 19.1 & 15.1 & 130.4 & 139.1 \\
\hline
\end{tabular}

Table 4 Effective inventory for Case I (No legislation) 
Maynard: The Effects of Anti-Price Gouging Legislation on Supply Chain Dynamics

\begin{tabular}{|c|c|c|c|c|}
\hline Time (Week) & R Eff Inv Case II & W Eff Inv Case II & D Eff Inv Case II & F Eff Inv Case II \\
\hline 0.0 & 12.0 & 12.0 & 12.0 & 12.0 \\
\hline 1.0 & 12.0 & 12.0 & 12.0 & 12.0 \\
\hline 2.0 & 12.0 & 12.0 & 12.3 & 12.3 \\
\hline 3.0 & 12.0 & 12.0 & 12.5 & 12.5 \\
\hline 4.0 & 12.0 & 11.7 & 12.5 & 12.9 \\
\hline 5.0 & 12.0 & 11.5 & 12.5 & 13.3 \\
\hline 6.0 & 8.0 & 11.2 & 12.1 & 13.3 \\
\hline 7.0 & 4.0 & 7.8 & 11.6 & 13.3 \\
\hline 8.0 & 0.0 & -0.6 & 11.0 & 12.6 \\
\hline 9.0 & -0.9 & -10.2 & 6.4 & 11.7 \\
\hline 10.0 & 2.8 & -20.9 & -5.2 & 10.5 \\
\hline 11.0 & -1.4 & -28.1 & -20.0 & 4.2 \\
\hline 12.0 & -5.4 & -32.4 & -38.4 & -11.8 \\
\hline 13.0 & -5.5 & -44.2 & -53.5 & -34.3 \\
\hline 14.0 & -3.5 & -57.1 & -70.3 & -64.4 \\
\hline 15.0 & -7.7 & -65.1 & -94.7 & -93.0 \\
\hline 16.0 & -11.8 & -74.4 & -122.8 & -111.0 \\
\hline 17.0 & -10.6 & -88.9 & -145.9 & -126.1 \\
\hline 18.0 & -11.2 & -104.3 & -156.4 & -136.4 \\
\hline 19.0 & -15.6 & -112.9 & -158.9 & -141.6 \\
\hline 20.0 & -19.4 & -107.8 & -151.0 & -142.5 \\
\hline 21.0 & -16.5 & -91.8 & -132.7 & -135.3 \\
\hline 22.0 & 0.5 & -62.3 & -105.7 & -117.8 \\
\hline 23.0 & 29.8 & -20.4 & -63.4 & -89.3 \\
\hline 24.0 & 74.2 & 33.2 & -2.7 & -49.7 \\
\hline 25.0 & 130.3 & 107.5 & 75.8 & 5.2 \\
\hline 26.0 & 160.6 & 203.7 & 174.4 & 78.1 \\
\hline 27.0 & 162.3 & 231.4 & 277.3 & 169.4 \\
\hline 28.0 & 154.3 & 238.9 & 309.6 & 244.9 \\
\hline 29.0 & 146.3 & 238.9 & 312.4 & 293.5 \\
\hline 30.0 & 138.3 & 238.9 & 312.4 & 303.7 \\
\hline 31.0 & 130.3 & 238.9 & 312.4 & 303.7 \\
\hline 32.0 & 122.3 & 238.9 & 312.4 & 303.7 \\
\hline 33.0 & 114.3 & 238.9 & 312.4 & 303.7 \\
\hline 34.0 & 106.3 & 238.9 & 312.4 & 303.7 \\
\hline 35.0 & 98.3 & 238.9 & 312.4 & 303.7 \\
\hline 36.0 & 90.3 & 238.9 & 312.4 & 303.7 \\
\hline
\end{tabular}

Table 5 Effective inventory for Case II (Price rigidity) 
Maynard: The Effects of Anti-Price Gouging Legislation on Supply Chain Dynamics

\begin{tabular}{|c|c|c|c|c|}
\hline Time (Week) & R Eff Inv Case III & W Eff Inv Case III & D Eff Inv Case III & F Eff Inv Case III \\
\hline 0.0 & 12.0 & 12.0 & 12.0 & 12.0 \\
\hline 1.0 & 12.0 & 12.0 & 12.0 & 12.0 \\
\hline 2.0 & 12.0 & 12.0 & 12.3 & 12.3 \\
\hline 3.0 & 12.0 & 12.0 & 12.5 & 12.5 \\
\hline 4.0 & 12.0 & 11.7 & 12.5 & 12.9 \\
\hline 5.0 & 12.0 & 11.5 & 12.5 & 13.3 \\
\hline 6.0 & 8.0 & 11.2 & 12.1 & 13.3 \\
\hline 7.0 & 4.0 & 7.8 & 11.6 & 13.3 \\
\hline 8.0 & 0.0 & -0.6 & 11.0 & 12.6 \\
\hline 9.0 & -0.9 & -10.2 & 6.4 & 11.7 \\
\hline 10.0 & 2.8 & -20.9 & -5.2 & 10.5 \\
\hline 11.0 & -1.4 & -28.1 & -20.0 & 4.2 \\
\hline 12.0 & -5.4 & -32.4 & -38.4 & -11.8 \\
\hline 13.0 & -5.5 & -44.2 & -53.5 & -34.3 \\
\hline 14.0 & -3.5 & -57.1 & -70.3 & -64.4 \\
\hline 15.0 & -7.7 & -65.1 & -94.7 & -93.0 \\
\hline 16.0 & -11.8 & -74.4 & -122.8 & -111.0 \\
\hline 17.0 & -10.6 & -88.9 & -145.9 & -126.1 \\
\hline 18.0 & -11.2 & -104.3 & -156.4 & -136.4 \\
\hline 19.0 & -15.6 & -112.9 & -158.9 & -141.6 \\
\hline 20.0 & -19.4 & -107.8 & -151.0 & -142.5 \\
\hline 21.0 & -16.5 & -91.8 & -132.7 & -135.3 \\
\hline 22.0 & 0.5 & -62.3 & -105.7 & -117.8 \\
\hline 23.0 & 29.8 & -20.4 & -63.4 & -89.3 \\
\hline 24.0 & 74.2 & 33.2 & -2.7 & -49.7 \\
\hline 25.0 & 130.1 & 107.5 & 75.8 & 5.2 \\
\hline 26.0 & 159.1 & 203.7 & 174.4 & 78.1 \\
\hline 27.0 & 158.8 & 231.4 & 277.3 & 169.4 \\
\hline 28.0 & 147.8 & 238.9 & 309.6 & 244.9 \\
\hline 29.0 & 136.2 & 238.9 & 312.4 & 293.5 \\
\hline 30.0 & 124.1 & 238.9 & 312.4 & 303.7 \\
\hline 31.0 & 111.4 & 238.9 & 312.4 & 303.7 \\
\hline 32.0 & 98.2 & 238.9 & 312.4 & 303.7 \\
\hline 33.0 & 84.8 & 238.9 & 312.4 & 303.7 \\
\hline 34.0 & 71.1 & 238.9 & 312.4 & 303.7 \\
\hline 35.0 & 57.3 & 237.1 & 312.4 & 303.7 \\
\hline 36.0 & 43.3 & 231.4 & 312.4 & 303.7 \\
\hline
\end{tabular}

Table 6 Effective inventory for Case III (APG legislation) 
Maynard: The Effects of Anti-Price Gouging Legislation on Supply Chain Dynamics

\begin{tabular}{|c|c|c|c|c|}
\hline Time (Week) & R placed Case I & W placed Case I & D placed Case I & F placed Case I \\
\hline 0 & 4 & 3.725440025 & 3.725440025 & 3.725440025 \\
\hline 1 & 4 & 3.731721878 & 3.731721878 & 3.731721878 \\
\hline 2 & 4 & 3.737860203 & 3.391914606 & 3.391914606 \\
\hline 3 & 4 & 3.743857861 & 3.342357159 & 3.342357159 \\
\hline 4 & 4 & 3.814822197 & 3.360489607 & 2.924598217 \\
\hline 5 & 7.119999886 & 3.882673025 & 3.378136396 & 2.792273045 \\
\hline 6 & 11.97138596 & 3.947515965 & 3.559371948 & 2.815954685 \\
\hline 7 & 12.4063797 & 7.940652847 & 3.762739658 & 2.854948044 \\
\hline 8 & 12.4593811 & 14.81834602 & 3.971005917 & 3.202818394 \\
\hline 9 & 11.1280098 & 17.2192955 & 9.136832237 & 3.649114132 \\
\hline 10 & 7.981572151 & 19.18172455 & 18.81424713 & 4.138630867 \\
\hline 11 & 6.919100761 & 18.42187119 & 24.36952209 & 10.90837669 \\
\hline 12 & 6.179563046 & 14.56627464 & 29.82001877 & 24.46846008 \\
\hline 13 & 4.42991209 & 14.07727146 & 31.00104523 & 34.93469238 \\
\hline 14 & 2.328831196 & 13.68072701 & 28.46346664 & 46.35773849 \\
\hline 15 & 2.40320158 & 10.60331345 & 30.11803436 & 51.9517746 \\
\hline 16 & 2.660075903 & 7.105215549 & 31.60802269 & 49.82408142 \\
\hline 17 & 1.535063744 & 6.776573658 & 27.97768593 & 49.88564682 \\
\hline 18 & 1.140218258 & 6.588666916 & 19.88485336 & 47.45999146 \\
\hline 19 & 2.100631952 & 3.125429153 & 12.57944107 & 37.69916153 \\
\hline 20 & 2.98110795 & 0 & 2.82442379 & 22.09955025 \\
\hline 21 & 1.916862965 & 0 & 0 & 5.730269909 \\
\hline 22 & 3.067676306 & 0 & 0 & 0 \\
\hline 23 & 4.633711815 & 0 & 0 & 0 \\
\hline 24 & 5.890757084 & 0 & 0 & 0 \\
\hline 25 & 7.322517872 & 0 & 0 & 0 \\
\hline 26 & 8.221029282 & 0 & 0 & 0 \\
\hline 27 & 8.345720291 & 0 & 0 & 0 \\
\hline 28 & 7.802650452 & 0 & 0 & 0 \\
\hline 29 & 6.668833733 & 0 & 0 & 0 \\
\hline 30 & 5.318812847 & 1.109237671 & 0 & 0 \\
\hline 31 & 4.202859879 & 1.683938503 & 0 & 0 \\
\hline 32 & 3.563123703 & 1.678280592 & 0 & 0 \\
\hline 33 & 3.476257801 & 1.616672039 & 0 & 0 \\
\hline 34 & 3.908203125 & 1.603336215 & 0 & 0 \\
\hline 35 & 4.699773788 & 1.98431778 & 0 & 0 \\
\hline 36 & 5.64404583 & 2.989040852 & 0 & 0 \\
\hline
\end{tabular}

Table 7 Orders placed for Case I (No legislation) 
Maynard: The Effects of Anti-Price Gouging Legislation on Supply Chain Dynamics

\begin{tabular}{|c|c|c|c|c|}
\hline Time (Week) & R placed Case II & W placed Case II & D placed Case II & F placed Case II \\
\hline 0 & 4 & 3.725440025 & 3.725440025 & 3.725440025 \\
\hline 1 & 4 & 3.731721878 & 3.731721878 & 3.731721878 \\
\hline 2 & 4 & 3.737860203 & 3.391914606 & 3.391914606 \\
\hline 3 & 4 & 3.743857861 & 3.342357159 & 3.342357159 \\
\hline 4 & 4 & 3.814822197 & 3.360489607 & 2.924598217 \\
\hline 5 & 7.119999886 & 3.882673025 & 3.378136396 & 2.792273045 \\
\hline 6 & 12.23138523 & 3.947515965 & 3.559371948 & 2.815954685 \\
\hline 7 & 13.45971966 & 7.940652847 & 3.762739658 & 2.854948044 \\
\hline 8 & 14.71615791 & 15.14594555 & 3.971005917 & 3.202818394 \\
\hline 9 & 15.1187582 & 18.60660934 & 9.136832237 & 3.649114132 \\
\hline 10 & 14.25373268 & 22.32749367 & 19.22702217 & 4.138630867 \\
\hline 11 & 15.56152821 & 24.26723099 & 26.19326782 & 10.90837669 \\
\hline 12 & 16.88090134 & 24.19006729 & 34.17839432 & 24.98855591 \\
\hline 13 & 17.10088539 & 28.09816742 & 39.47908401 & 37.32803345 \\
\hline 14 & 16.75328445 & 32.22208405 & 43.02814484 & 52.36412811 \\
\hline 15 & 18.15219688 & 33.9845314 & 52.39200592 & 64.14469147 \\
\hline 16 & 19.52420044 & 35.45531464 & 62.7135849 & 71.48815155 \\
\hline 17 & 19.46628952 & 39.89730072 & 69.29052734 & 83.98706818 \\
\hline 18 & 19.89213562 & 44.45138931 & 72.46903992 & 96.27597046 \\
\hline 19 & 21.39500809 & 45.85107422 & 76.77501678 & 103.4556732 \\
\hline 20 & 22.79378891 & 44.47451782 & 78.71327209 & 106.1577911 \\
\hline 21 & 22.30954933 & 41.67128754 & 75.02328491 & 108.0813751 \\
\hline 22 & 17.83123016 & 35.62643433 & 66.54229736 & 105.1832199 \\
\hline 23 & 9.75985527 & 24.91755676 & 53.13610077 & 94.06128693 \\
\hline 24 & 0 & 7.553972244 & 32.3094101 & 75.55703735 \\
\hline 25 & 0 & 0 & 2.808450699 & 48.60923004 \\
\hline 26 & 0 & 0 & 0 & 10.12976456 \\
\hline 27 & 0 & 0 & 0 & 0 \\
\hline 28 & 0 & 0 & 0 & 0 \\
\hline 29 & 0 & 0 & 0 & 0 \\
\hline 30 & 0 & 0 & 0 & 0 \\
\hline 31 & 0 & 0 & 0 & 0 \\
\hline 32 & 0 & 0 & 0 & 0 \\
\hline 33 & 0 & 0 & 0 & 0 \\
\hline 34 & 0 & 0 & 0 & 0 \\
\hline 35 & 0 & 0 & 0 & 0 \\
\hline 36 & 0 & 0 & 0 & 0 \\
\hline
\end{tabular}

Table 8 Orders placed for Case II (Price rigidity) 
Maynard: The Effects of Anti-Price Gouging Legislation on Supply Chain Dynamics

\begin{tabular}{|c|c|c|c|c|}
\hline Time (Week) & R placed Case III & W placed Case III & D placed Case III & F placed Case III \\
\hline 0 & 4 & 3.725440025 & 3.725440025 & 3.725440025 \\
\hline 1 & 4 & 3.731721878 & 3.731721878 & 3.731721878 \\
\hline 2 & 4 & 3.737860203 & 3.391914606 & 3.391914606 \\
\hline 3 & 4 & 3.743857861 & 3.342357159 & 3.342357159 \\
\hline 4 & 4 & 3.814822197 & 3.360489607 & 2.924598217 \\
\hline 5 & 7.119999886 & 3.882673025 & 3.378136396 & 2.792273045 \\
\hline 6 & 12.23138523 & 3.947515965 & 3.559371948 & 2.815954685 \\
\hline 7 & 13.45971966 & 7.940652847 & 3.762739658 & 2.854948044 \\
\hline 8 & 14.71615791 & 15.14594555 & 3.971005917 & 3.202818394 \\
\hline 9 & 15.1187582 & 18.60660934 & 9.136832237 & 3.649114132 \\
\hline 10 & 14.25373268 & 22.32749367 & 19.22702217 & 4.138630867 \\
\hline 11 & 15.56152821 & 24.26723099 & 26.19326782 & 10.90837669 \\
\hline 12 & 16.88090134 & 24.19006729 & 34.17839432 & 24.98855591 \\
\hline 13 & 17.10088539 & 28.09816742 & 39.47908401 & 37.32803345 \\
\hline 14 & 16.75328445 & 32.22208405 & 43.02814484 & 52.36412811 \\
\hline 15 & 18.15219688 & 33.9845314 & 52.39200592 & 64.14469147 \\
\hline 16 & 19.52420044 & 35.45531464 & 62.7135849 & 71.48815155 \\
\hline 17 & 19.46628952 & 39.89730072 & 69.29052734 & 83.98706818 \\
\hline 18 & 19.89213562 & 44.45138931 & 72.46903992 & 96.27597046 \\
\hline 19 & 21.39500809 & 45.85107422 & 76.77501678 & 103.4556732 \\
\hline 20 & 22.79378891 & 44.47451782 & 78.71327209 & 106.1577911 \\
\hline 21 & 22.30954933 & 41.67128754 & 75.02328491 & 108.0813751 \\
\hline 22 & 17.83123016 & 35.62643433 & 66.54229736 & 105.1832199 \\
\hline 23 & 9.75985527 & 24.91755676 & 53.13610077 & 94.06128693 \\
\hline 24 & 0 & 7.553972244 & 32.3094101 & 75.55703735 \\
\hline 25 & 0 & 0 & 2.808450699 & 48.60923004 \\
\hline 26 & 0 & 0 & 0 & 10.12976456 \\
\hline 27 & 0 & 0 & 0 & 0 \\
\hline 28 & 0 & 0 & 0 & 0 \\
\hline 29 & 0 & 0 & 0 & 0 \\
\hline 30 & 0 & 0 & 0 & 0 \\
\hline 31 & 0 & 0 & 0 & 0 \\
\hline 32 & 0 & 0 & 0 & 0 \\
\hline 33 & 1.814983368 & 0 & 0 & 0 \\
\hline 34 & 5.733280182 & 0 & 0 & 0 \\
\hline 35 & 9.696269989 & 0 & 0 & 0 \\
\hline 36 & 13.70718861 & 0 & 0 & 0 \\
\hline
\end{tabular}

Table 9 Orders placed for Case III (APG legislation) 
APPENDIX C

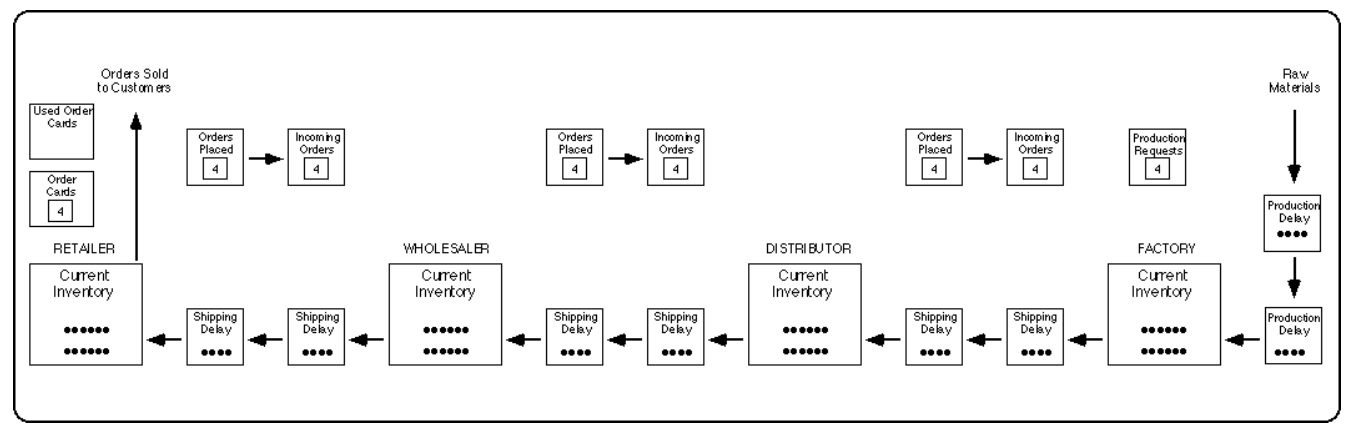

\section{Playing the Game}

The game is played on a board that portrays the production and distribution of beer (figures 1-2). Each team consists of four sectors: Retailer, Wholesaler, Distributor, and Factory $(R, W, D$, and $F)$ arranged in a linear distribution chain. One or two people manage each sector. Pennies stand for cases of beer. A deck of cards represents customer demand. Each simulated week, customers purchase from the retailer, who ships the beer requested out of inventory. The retailer in turn orders from the wholesaler, who ships the beer requested out of their own inventory. Likewise the wholesaler orders and receives beer from the distributor, who in turn orders and receives beer from the factory, where the beer is brewed. At each stage there are shipping delays and order processing delays. The players' objective is to minimize total team costs. Inventory holding costs are $\$ .50 /$ case/week. Backlog costs are \$1.00/case/week, to capture both the lost revenue and the ill will a stock out causes among customers. Costs are assessed at each link of the distribution chain.

The game can be played with anywhere from four to hundreds of people. Each person is asked to bet $\$ 1$, with the pot going to the team with the lowest total costs, winner takes all. The game is initialized in equilibrium. Each inventory contains 12 cases and initial throughput is four cases per week. In the first few weeks of the game the players learn the mechanics of filling orders, recording inventory, etc. During this time customer demand remains constant at four cases per week, and each player is directed to order four cases, maintaining the equilibrium. Beginning with week four the players are allowed to order any quantity they wish, and are told that customer demand may vary; one of their jobs is to forecast demand. Players are told the game will run for 50 simulated weeks, but play is actually halted after 36 weeks to avoid horizon effects.

Each player has good local information but severely limited global information. Players keep records of their inventory, backlog and orders placed with their 
supplier each week. However, people are directed not to communicate with one another; information is passed through orders and shipments. Customer demand is not known to any of the players in advance. Only the retailers discover customer demand as the game proceeds. The others learn only what their own customer orders.

These information limitations imply that the players are unable to coordinate their decisions or jointly plan strategy, even though the objective of each team is to minimize total costs. As in many real life settings, the global optimization problem must be factored into subproblems distributed throughout the organization.

The game is deceptively simple compared to real life. All you have to do is meet customer demand and order enough from your own supplier to keep your inventory low while avoiding costly backlogs. There are no machine breakdowns or other random events, no labor problems, no capacity limits or financial constraints. Yet the results are shocking.

(Sterman, 1992) 
APPENDIX D

\begin{tabular}{|c|c|c|c|c|c|c|}
\hline State & $\begin{array}{l}\text { Year } \\
\text { Passed }\end{array}$ & Fines & $\begin{array}{l}\text { Goods } \\
\text { Covered } \\
\end{array}$ & $\begin{array}{l}\text { Triggering } \\
\text { Event }\end{array}$ & $\begin{array}{l}\text { Criminal } \\
\text { Penalties }\end{array}$ & Ceiling \\
\hline $\mathrm{AL}$ & 1996 & $\begin{array}{l}\$ 1,000 / \text { viola } \\
\text { tion; } \\
\$ 25,000 \\
\text { max fine for } \\
24 \text { hours }\end{array}$ & $\begin{array}{l}\text { General } \\
\text { goods and } \\
\text { services }\end{array}$ & $\begin{array}{l}\text { Gov. } \\
\text { declared } \\
\text { SOE }\end{array}$ & None & $\begin{array}{l}25 \% \text { above } \\
\text { pre-emergency } \\
\text { prices }\end{array}$ \\
\hline AR & 1997 & $\begin{array}{l}\text { Provided in } \\
\text { law }\end{array}$ & $\begin{array}{l}\text { General } \\
\text { goods and } \\
\text { services }\end{array}$ & $\begin{array}{l}\text { President, } \\
\text { gov. or } \\
\text { locally } \\
\text { declared } \\
\text { SOE }\end{array}$ & $\begin{array}{l}\text { Provided in } \\
\text { law }\end{array}$ & $\begin{array}{l}10 \% \text { above } \\
\text { pre-emergency } \\
\text { prices }\end{array}$ \\
\hline $\mathrm{CA}$ & 1994 & $\begin{array}{l}\$ 10,000 \text { or } \\
\text { less }\end{array}$ & $\begin{array}{l}\text { General } \\
\text { goods and } \\
\text { services }\end{array}$ & $\begin{array}{l}\text { President, } \\
\text { gov. or } \\
\text { locally } \\
\text { declared } \\
\text { SOE }\end{array}$ & $\begin{array}{l}<1 \text { year in } \\
\text { prison }\end{array}$ & $\begin{array}{l}10 \% \text { above } \\
\text { pre-emergency } \\
\text { prices }\end{array}$ \\
\hline$\overline{\mathrm{CT}}$ & 1986 & $\begin{array}{l}\$ 1,000 \text { or } \\
\text { less }\end{array}$ & $\begin{array}{l}\text { Goods and } \\
\text { energy }\end{array}$ & $\begin{array}{l}\text { Gov. } \\
\text { declared } \\
\text { SOE }\end{array}$ & $\begin{array}{l}<1 \text { year in } \\
\text { prison }\end{array}$ & $\begin{array}{l}\text { Pre-emergency } \\
\text { prices }\end{array}$ \\
\hline FL & 1992 & Unspecified & $\begin{array}{l}\text { General } \\
\text { goods and } \\
\text { services }\end{array}$ & $\begin{array}{l}\text { Gov. } \\
\text { declared } \\
\text { SOE }\end{array}$ & None & $\begin{array}{l}\text { Pre-emergency } \\
\text { prices }\end{array}$ \\
\hline$\overline{G A}$ & 1995 & $\begin{array}{l}<\$ 10,000 / \\
\text { transaction }\end{array}$ & $\begin{array}{l}\text { General } \\
\text { goods and } \\
\text { services }\end{array}$ & $\begin{array}{l}\text { Gov. } \\
\text { declared } \\
\text { SOE }\end{array}$ & None & $\begin{array}{l}\text { Pre-emergency } \\
\text { prices }\end{array}$ \\
\hline $\mathrm{HI}$ & 1983 & Unspecified & $\begin{array}{l}\text { General } \\
\text { goods and } \\
\text { services }\end{array}$ & $\begin{array}{l}\text { Gov. } \\
\text { declared } \\
\text { SOE / } \\
\text { Severe } \\
\text { weather } \\
\text { warning } \\
\end{array}$ & None & $\begin{array}{l}\text { Pre-emergency } \\
\text { prices }\end{array}$ \\
\hline IA & 1993 & Unspecified & $\begin{array}{l}\text { General } \\
\text { goods and } \\
\text { services }\end{array}$ & "Disaster" & None & $\begin{array}{l}\text { Pre-emergency } \\
\text { prices }\end{array}$ \\
\hline ID & 2002 & Unspecified & $\begin{array}{l}\text { Food, fuel, } \\
\text { pharmaceuti } \\
\text { cals, water }\end{array}$ & $\begin{array}{l}\text { Gov. } \\
\text { declared } \\
\text { SOE }\end{array}$ & None & $\begin{array}{l}\text { Pre-emergency } \\
\text { prices }\end{array}$ \\
\hline IN & 2002 & $\begin{array}{l}\$ 1000 / \\
\text { transaction }\end{array}$ & Fuel & $\begin{array}{l}\text { Gov. } \\
\text { declared } \\
\text { SOE }\end{array}$ & None & $\begin{array}{l}\text { Pre-emergency } \\
\text { prices }\end{array}$ \\
\hline KS & 2002 & Unspecified & $\begin{array}{l}\text { General } \\
\text { goods and } \\
\text { services }\end{array}$ & $\begin{array}{l}\text { Gov. or } \\
\text { President } \\
\text { declared } \\
\text { SOE }\end{array}$ & None & $\begin{array}{l}25 \% \text { above } \\
\text { pre-emergency } \\
\text { prices }\end{array}$ \\
\hline KY & 2004 & $\begin{array}{l}<\$ 5,000 \text { for } \\
1 \text { st } \\
\text { violation, } \\
<\$ 10,000 \\
\text { afterwards }\end{array}$ & $\begin{array}{l}\text { General } \\
\text { goods and } \\
\text { services }\end{array}$ & $\begin{array}{l}\text { Gov. or } \\
\text { President } \\
\text { declared } \\
\text { SOE }\end{array}$ & None & $\begin{array}{l}\text { Pre-emergency } \\
\text { prices }\end{array}$ \\
\hline LA & 1993 & $\begin{array}{l}\text { Provided in } \\
\text { law }\end{array}$ & $\begin{array}{l}\text { General } \\
\text { goods and } \\
\text { services }\end{array}$ & $\begin{array}{l}\text { President, } \\
\text { gov. } \\
\text { declared }\end{array}$ & $\begin{array}{l}\text { Provided in } \\
\text { law }\end{array}$ & $\begin{array}{l}\text { Pre-emergency } \\
\text { prices }\end{array}$ \\
\hline
\end{tabular}




\begin{tabular}{|c|c|c|c|c|c|c|}
\hline & & & & $\begin{array}{l}\text { SOE or } \\
\text { hurricane } \\
\text { threat in } \\
\text { Gulf }\end{array}$ & & \\
\hline MA & 1990 & Unspecified & Petroleum & $\begin{array}{l}\text { "Market } \\
\text { emergency" }\end{array}$ & None & $\begin{array}{l}\text { Pre-emergency } \\
\text { prices }\end{array}$ \\
\hline $\mathrm{ME}$ & 2006 & $\begin{array}{l}\text { Provided in } \\
\text { law }\end{array}$ & $\begin{array}{l}\text { General } \\
\text { goods and } \\
\text { services }\end{array}$ & $\begin{array}{l}\text { Gov. } \\
\text { declared } \\
\text { "abnormal } \\
\text { market } \\
\text { disruption" }\end{array}$ & None & $\begin{array}{l}15 \% \text { above } \\
\text { pre-emergency } \\
\text { prices }\end{array}$ \\
\hline $\mathrm{MO}$ & 1994 & Unspecified & $\begin{array}{l}\text { "Necessities } \\
\text { " }\end{array}$ & $\begin{array}{l}\text { Not clearly } \\
\text { specified }\end{array}$ & None & $\begin{array}{l}\text { "Excessive } \\
\text { prices" }\end{array}$ \\
\hline MS & 1986 & $<\$ 500$ & $\begin{array}{l}\text { General } \\
\text { goods and } \\
\text { services }\end{array}$ & $\begin{array}{l}\text { SOE (no } \\
\text { declaration } \\
\text { required) }\end{array}$ & $\begin{array}{l}0-5 \text { years in } \\
\text { prison }\end{array}$ & $\begin{array}{l}\text { Pre-emergency } \\
\text { prices }\end{array}$ \\
\hline $\mathrm{NC}$ & 2003 & Unspecified & $\begin{array}{l}\text { General } \\
\text { goods and } \\
\text { services }\end{array}$ & $\begin{array}{l}\text { Gov. } \\
\text { declared } \\
\text { SOE }\end{array}$ & None & $\begin{array}{l}\text { "Unconsciona } \\
\text { bly excessive" } \\
\text { prices }\end{array}$ \\
\hline NJ & 2001 & Unspecified & $\begin{array}{l}\text { General } \\
\text { goods and } \\
\text { services }\end{array}$ & $\begin{array}{l}\text { President, } \\
\text { gov. or } \\
\text { locally } \\
\text { declared } \\
\text { SOE }\end{array}$ & None & $\begin{array}{l}10 \% \text { above } \\
\text { pre-emergency } \\
\text { prices }\end{array}$ \\
\hline $\mathrm{NY}$ & 1979 & $\begin{array}{l}<\$ 10,000 \\
\text { and } \\
\text { restitution }\end{array}$ & $\begin{array}{l}\text { General } \\
\text { goods and } \\
\text { services }\end{array}$ & $\begin{array}{l}\text { Gov. } \\
\text { declared } \\
\text { SOE }\end{array}$ & None & $\begin{array}{l}\text { Pre-emergency } \\
\text { prices }\end{array}$ \\
\hline $\mathrm{OK}$ & 1999 & Unspecified & $\begin{array}{l}\text { General } \\
\text { goods and } \\
\text { services }\end{array}$ & $\begin{array}{l}\text { Gov. or } \\
\text { President } \\
\text { declared } \\
\text { SOE }\end{array}$ & None & $\begin{array}{l}10 \% \text { above } \\
\text { pre-emergency } \\
\text { prices }\end{array}$ \\
\hline OR & 2007 & NA & NA & NA & NA & NA \\
\hline $\mathrm{PA}$ & 2006 & $\begin{array}{l}<\$ 10,000 / \\
\text { violation } \\
\text { plus } \\
\text { restitution }\end{array}$ & $\begin{array}{l}\text { General } \\
\text { goods and } \\
\text { services }\end{array}$ & $\begin{array}{l}\text { Gov. } \\
\text { declared } \\
\text { SOE }\end{array}$ & None & $\begin{array}{l}\text { Pre-emergency } \\
\text { prices }\end{array}$ \\
\hline $\mathrm{SC}$ & 2002 & $<\$ 1,000$ & $\begin{array}{l}\text { General } \\
\text { goods and } \\
\text { services }\end{array}$ & $\begin{array}{l}\text { Gov. or } \\
\text { President } \\
\text { declared } \\
\text { SOE } \\
\end{array}$ & $\begin{array}{l}<30 \text { days in } \\
\text { prison }\end{array}$ & $\begin{array}{l}\text { Pre-emergency } \\
\text { prices }\end{array}$ \\
\hline $\mathrm{TN}$ & 2002 & Unspecified & $\begin{array}{l}\text { General } \\
\text { goods and } \\
\text { services }\end{array}$ & $\begin{array}{l}\text { Gov. or } \\
\text { President } \\
\text { declared } \\
\text { SOE }\end{array}$ & None & $\begin{array}{l}\text { Pre-emergency } \\
\text { prices }\end{array}$ \\
\hline $\mathrm{TX}$ & 1995 & Unspecified & $\begin{array}{l}\text { General } \\
\text { goods and } \\
\text { services }\end{array}$ & $\begin{array}{l}\text { Gov. } \\
\text { declared } \\
\text { SOE }\end{array}$ & None & $\begin{array}{l}\text { "Excessive or } \\
\text { exorbitant } \\
\text { prices" }\end{array}$ \\
\hline UT & 2005 & $\begin{array}{l}<\$ 1,000 / \\
\text { violation or } \\
\$ 10,000 \\
\text { total }\end{array}$ & $\begin{array}{l}\text { General } \\
\text { goods and } \\
\text { services }\end{array}$ & $\begin{array}{l}\text { Gov. or } \\
\text { President } \\
\text { declared } \\
\text { SOE }\end{array}$ & None & $\begin{array}{l}\text { Pre-emergency } \\
\text { prices }\end{array}$ \\
\hline VA & 2004 & Unspecified & $\begin{array}{l}\text { General } \\
\text { goods and } \\
\text { services }\end{array}$ & $\begin{array}{l}\text { Gov. or } \\
\text { President } \\
\text { declared } \\
\text { SOE }\end{array}$ & None & $\begin{array}{l}\text { Pre-emergency } \\
\text { prices }\end{array}$ \\
\hline
\end{tabular}




\begin{tabular}{|l|l|l|l|l|l|l|}
\hline VT & 2006 & Unspecified & $\begin{array}{l}\text { "Petroleum } \\
\text { or heating } \\
\text { fuel } \\
\text { products" }\end{array}$ & $\begin{array}{l}\text { "abnormal } \\
\text { disruption of } \\
\text { any market } \\
\text { for } \\
\text { petroleum } \\
\text { products or } \\
\text { heating fuel } \\
\text { products" }\end{array}$ & None & $\begin{array}{l}\text { Pre-emergency } \\
\text { prices }\end{array}$ \\
\hline WI & 2006 & $<\$ 10,000$ & $\begin{array}{l}\text { General } \\
\text { goods and } \\
\text { services }\end{array}$ & $\begin{array}{l}\text { Gov. } \\
\text { declared } \\
\text { "abnormal } \\
\text { economic } \\
\text { disruption" }\end{array}$ & None & $\begin{array}{l}\text { "Excessive } \\
\text { prices" }\end{array}$ \\
\hline WV & 2002 & $<\$ 1,000$ & $\begin{array}{l}\text { General } \\
\text { goods and } \\
\text { services }\end{array}$ & $\begin{array}{l}\text { Gov. or } \\
\text { President } \\
\text { declared } \\
\text { SOE }\end{array}$ & prison & $\begin{array}{l}<1 \text { year in } \\
\text { pre-emergency } \\
\text { prices }\end{array}$ \\
\hline
\end{tabular}

Table 10 Anti-price gouging legislation by state (Davis, 2008) 